Doering et al. Hypoxia

.

\title{
Nuclear Hormone Receptor NHR-49 controls a HIF-1-independent hypoxia adaptation pathway in Caenorhabditis elegans
}

Kelsie R. S. Doering ${ }^{1-3}$, Xuanjin Cheng ${ }^{2-4}$, Luke Milburn ${ }^{5}$, Ramesh Ratnappan ${ }^{6}$, Arjumand Ghazi $^{6,7}$, Dana L. Miller ${ }^{5}$, and Stefan Taubert ${ }^{1-4^{*}}$

6

7

British Columbia, Canada, ${ }^{2}$ Centre for Molecular Medicine and Therapeutics, The University of British

Columbia, Vancouver, British Columbia, Canada, ${ }^{3}$ British Columbia Children's Hospital Research Institute, Vancouver, British Columbia, Canada, ${ }^{4}$ Department of Medical Genetics, The University of British Columbia, Vancouver, British Columbia, Canada, ${ }^{5}$ Department of Biochemistry, University of Washington, Seattle, Washington, USA, ${ }^{6}$ Department of Pediatrics, University of Pittsburgh School of Medicine, ${ }^{7}$ Departments of Developmental Biology and Cell Biology and Physiology, University of Pittsburgh School of Medicine, Pittsburgh, Pennsylvania, USA

Keywords: hypoxia, autophagy, detoxification, HIF-1, NHR-49, HPK-1

Running title: HIF-independent hypoxia response 


\section{Abstract}

The response to insufficient oxygen (hypoxia) is orchestrated by the conserved Hypoxia-

Inducible Factor (HIF). However, HIF-independent hypoxia response pathways exist that act in parallel

to HIF to mediate the physiological hypoxia response. Here, we describe a HIF-independent hypoxia

response pathway controlled by Caenorhabditis elegans Nuclear Hormone Receptor NHR-49, an

orthologue of mammalian Peroxisome Proliferator-Activated Receptor alpha (PPAR $\alpha$ ). We show that

$n h r-49$ is required for worm survival in hypoxia and is synthetic lethal with hif-1 in this context,

demonstrating that these factors act independently. RNA-seq analysis shows that in hypoxia $n h r-49$

regulates a set of genes that are hif-1-independent, including autophagy genes that promote hypoxia

survival. We further show that Nuclear Hormone Receptor $n h r-67$ is a negative regulator and

Homeodomain-interacting Protein Kinase $h p k-1$ is a positive regulator of the NHR-49 pathway.

34 Together, our experiments define a new, essential hypoxia response pathway that acts in parallel to the well-known HIF-mediated hypoxia response. 


\section{Introduction}

Organisms are continuously exposed to endogenous and exogenous stresses, from suboptimal temperatures to foreign substances. Thus, an organism's ability to mount specific stress responses, including protecting healthy cells from harm or inducing apoptosis when damage to a cell cannot be overcome, is critical for survival. Hypoxia is a stress that occurs when cellular oxygen levels are too low for normal physiological functions. It occurs naturally in cells and tissues during development, as well as in many diseases (P. Lee et al., 2020; Powell-Coffman, 2010). For example, due to hyperproliferation, inadequate vascularization, and loss of matrix attachment, cancer cells grow in hostile microenvironments featuring hypoxia. Certain cancers thus hijack the hypoxia response to allow growth and metastasis in these harsh conditions (Rankin \& Giaccia, 2016; Schito \& Semenza, 2016; T. Zhang et al., 2019), and tumor hypoxia correlates with poor clinical outcome (Keith \& Simon, 2007).

Most prominently, mutations in the tumor suppressor von Hippel Lindau (VHL), which inhibits the transcription factor hypoxia-inducible factor (HIF), occur in kidney cancers, and the resulting accumulation of HIF drives tumor growth (Kaelin, 2008; M. Li \& Kim, 2011). In line with a pivotal role of HIF in these cancers are studies showing promising effects of HIF inhibitors in preclinical (Albadari et al., 2019; W. Chen et al., 2016; Cho et al., 2016) and clinical studies (Fallah \& Rini, 2019). However, a better understanding of the transcriptional hypoxia adaptation pathway is needed to pinpoint new drug targets and to gain a deeper insight into how cells, tissues, and organisms cope with hypoxia.

The pathways that regulate the response to hypoxia are evolutionarily conserved from the nematode worm Caenorhabditis elegans to humans. As in mammals, a key pathway in C. elegans involves the transcription factor HIF-1, which is critical for the cellular responses to, and the defense against hypoxia (Choudhry \& Harris, 2018; Jiang et al., 2001). To survive hypoxia, animals activate the EGL-Nine homolog (EGLN)-VHL-HIF pathway (egl-9-vhl-1-hif-1 in C. elegans). In normoxic conditions $\left(21 \% \mathrm{O}_{2}\right)$, HIF-1 is degraded and thus inactive. This occurs when EGL-9 adds a hydroxyl 
group onto a proline residue within HIF-1. The hydroxylated proline promotes binding of the E3 ubiquitin ligase VHL-1, leading to poly-ubiquitination and proteasomal degradation of HIF-1. However, in hypoxic conditions, EGL-9 is rendered inactive; hence, HIF-1 is stabilized and activates a hypoxia adaptation gene expression program (Epstein et al., 2001; Powell-Coffman, 2010).

Although the responses controlled by the HIF-1 master regulator are most studied, evidence for parallel transcriptional programs in hypoxia exists, from C. elegans to mammalian organisms. For example, the transcription factor B lymphocyte-induced maturation protein 1 (BLMP-1) has a hif-1independent hypoxia regulatory role in C. elegans (Padmanabha et al., 2015), as does the conserved nuclear hormone receptor (NHR) estrogen-related receptor (dERR) in Drosophila melanogaster (Y. Li et al., 2013), and the cargo receptor Sequestosome 1 (SQSTM1/p62) in mammals (Pursiheimo et al., 2009). Thus, despite the evolutionarily conserved and important role of the HIF family, robust and effective hypoxia adaptation requires an intricate network of factors that act in concert. Compared to HIF, there is far less known about the mechanisms by which these pathways contribute to the hypoxia response.

C. elegans NHR-49 is a transcription factor orthologous to mammalian hepatocyte nuclear factor 4 (HNF4) and peroxisome proliferator-activated receptor $\alpha$ (PPAR $\alpha)$ (K. Lee et al., 2016). Similar to these NHRs, it controls lipid metabolism by activating genes involved in fatty acid desaturation and mitochondrial $\beta$-oxidation (Pathare et al., 2012; Marc R. Van Gilst et al., 2005). By maintaining lipid homeostasis, NHR-49 is able to extend lifespan, a phenotype often associated with stress resistance (Burkewitz et al., 2015; Ratnappan et al., 2014). In addition to regulating lipid metabolism, NHR-49 also regulates putative xenobiotic detoxification genes in a dietary restriction-like state and during starvation (Chamoli et al., 2014; Goh et al., 2018), is required for resistance to oxidative stress (Goh et al., 2018), and activates innate immune response programs upon infection of $C$. elegans with Staphylococcus aureus (Wani et al., 2020), Pseudomonas aeruginosa (Naim et al., 2020), and Enterococcus faecalis (Dasgupta et al., 2020). Moreover, a recent report showed that $n h r-49$ is 
required to increase expression of the Catechol-O-Methyl-Transferase comt-5 downstream of the

88 Hypoxia Inhibited Receptor tyrosine kinase hir-1, which mediates extracellular matrix remodelling in

89 hypoxia (Vozdek et al., 2018). However, the role of $n h r-49$ in hypoxia and how it intersects with hif-1

90 have not been explored.

91 The detoxification gene flavin mono-oxygenase 2 (fmo-2) is induced in many of the

92 aforementioned stresses in an nhr-49-dependent manner (Dasgupta et al., 2020; Goh et al., 2018; Wani

93 et al., 2020). Interestingly, fmo-2 is also a hif-1-dependent hypoxia response gene (Leiser et al., 2015;

94 Shen et al., 2005), but its dependence on $n h r-49$ in hypoxia is not known. We hypothesized that $n h r-49$

95 may play a role in the worm hypoxia response, in part by regulating fmo-2 expression. Here, we show

96 that $n h r-49$ is not only required to induce $f m o-2$, but controls a broad transcriptional response to

97 hypoxia, including the induction of autophagy genes that are also required for survival in hypoxia. Our

98 epistasis experiments indicate that $n h r-49$ is functionally required independently of hif- 1 in hypoxia.

99 Finally, we identify the protein kinase homeodomain interacting protein kinase 1 (hpk-1) as an

100 upstream activator and the transcription factor $n h r-67$ as a repressor of the $n h r-49$ hypoxia response

101 pathway. Together, our data define NHR-49 as a core player in a novel hypoxia response pathway that

102 acts independently of hif-1.

103 


\section{Results}

\section{$n h r-49$ is required to induce the expression of fmo-2 in hypoxia}

C. elegans fmo-2 is induced by oxidative stress, starvation, and pathogen infection in an $n h r-49$ -

107 dependent fashion (Dasgupta et al., 2020; Goh et al., 2018; Wani et al., 2020). fmo-2 expression is also

108 induced in a hif-1-dependent manner during hypoxia $\left(0.1 \% \mathrm{O}_{2}\right.$; Leiser et al., 2015; Shen et al., 2005$)$.

109 To test whether $n h r-49$ regulates fmo-2 expression in hypoxia, we quantified fmo- 2 mRNA levels in 110 normoxia $\left(21 \% \mathrm{O}_{2}\right)$ and hypoxia $\left(0.5 \% \mathrm{O}_{2}\right)$ by quantitative Reverse Transcription PCR (qRT-PCR) in

111 wild-type and mutant worms. The $n r 2041$ allele deletes portions of both the DNA binding domain and

112 the ligand binding domain of $n h r-49$ and is a predicted molecular null allele (Liu et al., 1999), and the

113 ia4 allele deletes exons 2-4 of hif- 1 and is also a predicted null allele (Jiang et al., 2001). In wild-type

114 worms, fmo-2 transcript levels increased approximately 40-fold in hypoxia, but this induction was

115 blocked in both $n h r-49(n r 2041)$ and hif-1(ia4) mutant worms (Figure 1A). Experiments using a

116 transgenic strain expressing a transcriptional Pfmo-2::gfp reporter (Goh et al., 2018) corroborated these

117 observations in vivo. In normoxia, this reporter is weakly expressed in some neurons and in the

118 intestine of transgenic animals, but expression was significantly elevated in the intestine of transgenic

119 worms in hypoxia (Figure 1B-C). High pharyngeal expression made it difficult to quantify neuronal

120 Pfmo-2::gfp in hypoxia. Consistent with our qRT-PCR data, loss of $n h r-49$ abrogated the increase in

121 intestinal upregulation of Pfmo-2::gfp worms following hypoxia exposure. We conclude that $n h r-49$ is 122 required to induce $f m o-2$ in hypoxia.

$124 n h r-49$ is required throughout the $C$. elegans life cycle to promote hypoxia resistance independently of hif-1

Wild-type embryos can survive a $24 \mathrm{~h}$ exposure to environments with as little as $0.5 \% \mathrm{O}_{2}$,

127 dependent on the presence of hif-1 (Jiang et al., 2001; Nystul \& Roth, 2004). We wanted to determine

128 if $n h r-49$, like hif-1, is functionally required for worm survival during hypoxia. We first assessed the 
ability of worm embryos to survive for 24 hours in $0.5 \% \mathrm{O}_{2}$ and then recover to the $\mathrm{L} 4$ or later stage

130 when placed back in normoxia for 65 hours. We found that $86 \%$ of wild-type worm embryos reached at least the L4 stage, while only $25 \%$ of $n h r-49$ and hif- 1 null mutant worms reached at least the L4 stage by that time (Figure 2A). This shows that, like hif-1, nhr-49 is required for embryo survival in hypoxia. Next, we asked whether $n h r-49$ acts in the hif- 1 hypoxia response pathway or in a separate, parallel response pathway. To address this question, we generated a $n h r-49(n r 2041) ; h i f-1$ (ia4) double null mutant. We observed that less than $2 \%$ of $n h r-49 ;$ hif -1 double null mutants reached at least the L4 stage following hypoxia exposure (Figure 2A). This suggests that $n h r-49$ and hif-1 act in separate, genetically independent hypoxia response pathways.

To determine if $n h r-49$ and hif-1 are required for larval development in hypoxia, we exposed newly hatched, first stage (L1) larvae to hypoxia for 48 hours. Following this treatment, 95\% of wildtype worms reached at least the L4 stage (Figure 2B). In contrast, only $19 \%$ of $n h r-49$ and only $20 \%$ of hif-1 mutant worms, respectively, reached at least the L4 stage, and no nhr-49; hif-1 double null mutant worms survived and developed to L4 (Figure 2B). Together, these results show that $n h r-49$ is required for worm adaptation to hypoxia independently of hif-1 both during embryogenesis and postembryonically.

In normal conditions, $n h r-49$ null worms have a shortened lifespan (Marc R. Van Gilst et al., specific requirement for $n h r-49$ in the hypoxia response, we studied worm development in normoxia.

149 We found that loss of $n h r-49$ had no effect on worm survival from embryo to at least the L4 stage at $15021 \% \mathrm{O}_{2}$ (Supplementary Figure 1A, Supplementary Table 1). Additionally, at 21\% $\mathrm{O}_{2}, n h r-49$ null 151 mutants did not significantly develop slower than wildtype worms (Supplementary Figure 1B, 152 Supplementary Table 2). Together, these data show that although $n h r-49$ null mutants display mild 
developmental defects in normoxia, the phenotypes observed are due to the requirement for $n h r-49$

154 specifically during hypoxia.

155

\section{$n h r-49$ is dispensable for survival in hydrogen sulfide}

To assess whether $n h r-49$ is involved other responses requiring hif-1, we next asked if it was required for adaptation to hydrogen sulfide $\left(\mathrm{H}_{2} \mathrm{~S}\right) . \mathrm{H}_{2} \mathrm{~S}$ is produced endogenously and is an important signalling molecule in animals, including in C. elegans (L. Li et al., 2011). However, exposure to high levels of hydrogen sulfide can be lethal. As in the hypoxia response, hif-1 is a master regulator of the requirement for $n h r-49$ is stress specific, and that $n h r-49$ does not participate in all hif-1-dependent expression in $\mathrm{H}_{2} \mathrm{~S}$ are quite different than those seen in hypoxia (Miller et al., 2011). Additionally, the this particular stress condition.

\section{The $n h r-49$-dependent transcriptional response to hypoxia includes $h$ if-1-independent genes}

To delineate the genes and biological processes regulated by NHR-49 in hypoxia, we analyzed whole-animal transcriptomes of wild-type, $n h r-49$, and hif- 1 worms before and after exposure to hypoxia significantly upregulated 718 genes and downregulated 339 genes more than two-fold in wild- 
178

179

180

181

182

183

184

185

186

188

189

190

191

192

193

194

195

196

197

198

199

200

201

202

et al., 2004; Shen et al., 2005), validating our approach. 315 of the upregulated and 177 of the

downregulated genes were dependent on $n h r-49$. Of these $n h r-49$ regulated genes, 83 of the

upregulated and 51 of the downregulated genes were hif-1-independent (Figure 3A, B). In line with our above data, fmo-2 was induced in an $n h r-49$-dependent manner (Figure 3C). However, although our qRT-PCR data (Figure 1A) show that fmo-2 induction is dependent on hif-1, our RNA-seq analysis excluded fmo-2 from the hif-1-dependent set because it retained more than two-fold induction in hypoxia vs. normoxia (Supplementary Figure 2B). This suggests that although fmo-2 induction is somewhat dependent on hif-1, it requires $n h r-49$. Thus, although many hypoxia responsive genes are controlled by both transcription factors, a subset is $n h r-49$-dependent but hif-1-independent.

We next performed functional enrichment analysis to identify the biological pathways and processes regulated in hypoxia, and specifically those dependent on $n h r-49$. In wild-type worms, pathways such as detoxification, response to heavy metal stress, and autophagy were induced (Supplementary Figure 2C), whereas processes such as amino acid transport and metabolism were downregulated (Supplementary Figure 2D). In the set of 83 genes that exclusively require $n h r-49$ but not hif-1 for induction in hypoxia (Figure 3C, Supplementary Table 3), autophagy and detoxification were significantly enriched (Figure 3D), suggesting a requirement for $n h r-49$ to regulate these particular processes in hypoxia. Interestingly, a separate set of detoxification genes was dependent only on hif-1 (Supplementary Figure 2E, F, Supplementary Table 4), and a third set of detoxification genes were independent of both $n h r-49$ and hif-1 (Supplementary Figure 2G, H, Supplementary Table 5).

This suggests that there may be an additional transcription factor(s) regulating this process in hypoxia. Our RNA-seq data revealed that the acyl-CoA synthetase gene acs-2 is induced in response to hypoxia in an $n h r-49$-dependent manner (Figure 3C, Supplementary Table 3). ACS-2 acts in the first step of mitochondrial fatty acid $\beta$-oxidation, and is strongly induced by NHR-49 during starvation and following exposure to E. faecalis (Dasgupta et al., 2020; Marc R. Van Gilst et al., 2005). To validate our RNA-seq data, we quantified acs-2 expression via qRT-PCR. Following hypoxia exposure, acs-2 
transcript levels increased approximately seven-fold, and this induction was blocked in the $n h r-49$ null

mutant, but not the hif-1 null mutant (Supplementary Figure 3A). We used a transgenic strain

expressing a transcriptional Pacs-2::gfp reporter to study this regulation in vivo (Burkewitz et al.,

2015). This reporter showed moderate GFP expression in the body of animals under normoxia, but

expression increased substantially in the intestine following exposure to hypoxia (Supplementary

Figure 3B, C). Consistent with our RNA-seq and qRT-PCR data, loss of $n h r-49$ blocked transcriptional

activation via the acs-2 promoter, as GFP was weaker in the intestines of these worms following

hypoxia exposure (Supplementary Figure 3B, C). Collectively, these data show that $n h r-49$ is

specifically required and that hif-1 is dispensable for induction of acs-2 in hypoxia.

\section{Autophagy genes are critical downstream targets of $n h r-49$ in hypoxia}

$$
\text { Next, we wanted to determine which of } n h r-49 \text { 's downstream transcriptional targets are }
$$
and acs-2(ok2457) embryos to survive hypoxia, as both genes are strongly induced during hypoxia in an $n h r-49$-dependent manner. Individually, loss of either fmo-2 (60\%) or acs-2 (65\%) did not significantly decrease embryo viability compared to wild-type (79\%) (Figure 3E). However, simultaneous loss of both fmo-2 and acs-2 resulted in a significant decrease in survival after hypoxia (47\%). None of the mutant animals showed embryo viability defects in normoxia, indicating that the phenotypes observed were specifically due to the requirement of these genes in hypoxia survival (Supplementary Figure 4A, Supplementary Table 1). These data suggest that fmo-2 and acs-2 each 
Notably, C. elegans show sensitivity to anoxia when the autophagy pathway is disrupted (Samokhvalov

et al., 2008), and autophagy is upregulated in anoxia (Chapin et al., 2015). However, the responses to

anoxia and hypoxia are mediated by different regulatory pathways (Nystul \& Roth, 2004), and it thus

was not a priori clear whether autophagy is also required for hypoxia resistance. To determine if

autophagy genes using feeding RNA interference (RNAi) in the wild-type and $n h r-49$ null mutant

backgrounds and assessed the ability of these embryos to survive hypoxia. RNAi mediated knockdown

of the autophagy genes atg-10 (28\%), atg-7 (41\%), bec-1 (27\%), and epg-3 (38\%) caused significant

sensitivity to hypoxia in the wild-type background compared to the empty vector (EV) control RNAi

treatment (79\%; Figure 3F). Importantly, the sensitivity of worms did not change when these genes

were knocked down in the $n h r-49$ null background $(32 \%, 25 \%, 13 \%, 13 \%$, respectively), suggesting

that these genes act in the same pathway as $n h r-49$. Depletion of these genes by RNAi alone did not

cause impaired development from embryo to L4 in normoxia, indicating the phenotypes observed were

specifically due to the requirement of these genes in hypoxia survival (Supplementary Figure 4B,

Supplementary Table 1). Together, these data show that autophagy is a functionally important $n h r-49$

regulated process required for worm survival in hypoxia.

\section{NHR-49 expression in multiple tissues is sufficient to promote hypoxia survival}

To test if $n h r-49$ activation is sufficient to promote survival of worms in hypoxia, we studied

the $n h r-49$ (et13) gain-of-function strain, which is sufficient to induce fmo-2 (Goh et al., 2018; K. Lee et 
251 eggs develop to at least L4 stage after 48 hours of hypoxia exposure, indicating that NHR-49 activation 252 is sufficient to improve the population survival of worms in hypoxia.

NHR-49 is expressed in multiple tissues, including the intestine, neurons, muscle, and

254 hypodermis (Ratnappan et al., 2014). Neuronal NHR-49 is sufficient to extend life span in some 255 contexts and regulates genes in distal tissues (Burkewitz et al., 2015), but where the protein acts to 256 regulate the response to hypoxia is unknown. To study this, we induced expression of an NHR-49::GFP 257 translational fusion protein in the $n h r-49(n r 2041)$ mutant background using tissue-specific promoters 258 (Naim et al., 2020). Comparing the NHR-49::GFP rescue strains to their non-GFP siblings, we found 259 that expressing $n h r-49$ in the intestine, neurons, hypodermis, or from its endogenous promoter was 260 sufficient to restore population survival to wild-type levels (Figure 4B). This suggests that NHR-49 can 261 act in multiple somatic tissues to regulate the organismal hypoxia response.

To determine if NHR-49 activity alone is sufficient to induce expression of hypoxia response genes, we assessed the ability of the $n h r-49$ (et13) gain-of-function strain to induce some of the $n h r-49$ dependent hypoxia response genes from our RNA-seq analysis in the absence of stress (Figure 4C). In 265 line with previous findings (Goh et al., 2018; K. Lee et al., 2016), $n h r-49$ was sufficient to induce fmo2 and acs-2 expression on its own. However, other hypoxia inducible $n h r-49$ regulated genes involved in autophagy and detoxification (Supplementary Table 3) were not induced in the $n h r$-49(et 13) gain-offunction mutant. It is possible that $n h r-49$ regulates autophagy indirectly in a manner independent of transcription, or that this et 13 mutation, which has combined gain and loss of function properties (K. Lee et al., 2016), cannot induce these tested autophagy genes. It is also possible that, to induce these genes, NHR-49 acts in concert with another hypoxia-responsive transcription factor, which is not activated in the $n h r-49$ (et 13) mutant. Together, this shows that NHR-49 is sufficient to extend survival of worms in hypoxia in various tissues, but the gain-of-function strain is only able to induce certain response genes without the presence of stress. 


\section{The nuclear hormone receptor NHR-67 negatively regulates the $n h r-49$ hypoxia response}

Cellular stress response pathways are intricate networks involving a multitude of proteins.

278

279

280

281

282

283

284

285

286

287

288

289

290

291

292

293

294

295

296

297

298

299

300

Activation or repression of downstream response genes thus often requires signaling via additional factors such as kinases and transcription factors. To identify additional factors acting in the $n h r-49$ regulated hypoxia response pathway, we studied proteins that have been reported to physically interact with NHR-49 (Reece-Hoyes et al., 2013). One such interaction partner is the nuclear hormone receptor NHR-67, the sole C. elegans ortholog of the D. melanogaster tailless and vertebrate NR2E1 genes (Gissendanner et al., 2004). NHR-67 is important in neural and uterine development (Fernandes \& Sternberg, 2007; Verghese et al., 2011), but a role for this NHR in stress responses has not yet been described. Our RNA-seq data showed that $n h r-67$ mRNA expression is modestly increased during hypoxia in wild-type worms, and much more substantially induced in the $n h r-49$ null background (Figure 5A), suggesting a possible regulatory interaction between these two NHRs during hypoxia. To explore this interaction further, we used feeding RNAi to knock down $n h r-67$ in normoxia and hypoxia, and observed how this affected the expression of the Pfmo-2::gfp and Pacs-2::gfp transcriptional reporters. Compared to $E V(R N A i)$, knockdown of $n h r-67$ significantly induced both reporters even in the absence of stress, suggesting a repressive role for $n h r-67$ on these genes (Figure 5B-E). In hypoxia, $n h r-67(R N A i)$ resulted in even higher expression of these reporters. In both normoxia and hypoxia, increased expression of the reporters was dependent on $n h r-49$, as loss of $n h r-49$ abrogated the GFP induction (Figure 5B-E). The $n h r-49$ (et13) gain-of-function mutation is sufficient to induce expression of the Pfmo-2::gfp reporter in non-stressed conditions (Goh et al., 2018), although it does not alter $n h r-$ 67 expression under normoxic conditions (Supplementary Figure 5A). Knockdown of $n h r-67$ further increased the expression of the Pfmo-2::gfp reporter in the $n h r-49$ (et13) background in both normoxia and hypoxia (Supplementary Figure 5B, C). Together, these data suggest that $n h r-67$ negatively regulates the expression of the hypoxia response genes fmo-2 and acs-2 in both normoxic and hypoxic conditions, and that this regulation is dependent on $n h r-49$. 
regulates this response, we used feeding RNAi to knock down $n h r-67$ and observed expression of the

Pnhr-49::nhr-49::gfp translational reporter (which encodes GFP tagged to a full length NHR-49

transgene under control of its endogenous promoter from extra-chromosomal arrays, henceforth

highly in the intestine, and also shows expression in neurons, muscle, and the hypodermis (Ratnappan

et al., 2014). Whole worm NHR-49::GFP expression was increased in both normoxia and hypoxia

following knockdown of $n h r-67$, with the highest increase observed in the intestine (Figure 5F, G).

This suggests that nhr-67 negatively regulates NHR-49, but in hypoxia, an increase in NHR-49 protein

311 levels may in turn repress $n h r-67$, suggesting a negative feedback loop. The effects seen on $f m o-2$ and acs-2 expression are likely a consequence of NHR-67's effect on NHR-49.

2007), so we used feeding RNAi to study $n h r-67$ 's functional requirements in hypoxia. We assessed the ability of $n h r-67(R N A i)$ embryos to survive hypoxia and recover, as described above. Resembling $n h r-$ 49(RNAi) worms (46\% survival), only $49 \%$ of $n h r-67$ knockdown embryos survived to at least L4 stage compared to the $E V(R N A i)$ worms (73\%; Supplementary Figure 5D). Although RNAi knockdown of $n h r-67$ and $n h r-49$ causes developmental delays, the majority of $n h r-67(R N A i)$ and $n h r-49(R N A i)$ worms were able to reach at least L4 stage in normoxia (91\% and 90\%, respectively), resembling EV(RNAi) worms (100\%; Supplementary Figure 5E, Supplementary Table 1). Thus, although $n h r-67$ appears to perform a negative regulatory role on the hypoxia pathway, it, too, is functionally required for survival in hypoxia. Taken together, these data show that $n h r-67$ is a functionally important negative regulator of the $n h r-49$-dependent hypoxia response. 
bioRxiv preprint doi: https://doi.org/10.1101/2021.02.24.432575; this version posted February 24, 2021. The copyright holder for this preprint

(which was not certified by peer review) is the author/funder. All rights reserved. No reuse allowed without permission.

Doering et al. Hypoxia

325

\section{The kinase $h p k$-1 positively regulates $n h r-49$-dependent hypoxia response genes and is required}

\section{for survival in hypoxia}

To identify additional factors acting in the $n h r-49$-dependent hypoxia response pathway, we studied eight kinases that we found to potentially act in the $n h r-49$-dependent oxidative stress response (Doering \& Taubert, manuscript in preparation). We depleted each kinase using feeding RNAi to determine if any treatment prevented Pfmo-2::gfp induction in hypoxia in the worm intestine. As expected, $n h r-49$ RNAi diminished this intestinal fluorescence compared to the EV(RNAi) (Figure 6A, B). Of the eight kinases tested, RNAi knockdown of the nuclear serine/threonine kinase homeodomain interacting protein kinase $1(h p k-1)$ significantly decreased intestinal Pfmo-2::gfp expression following hypoxia exposure (Figure 6A, B), phenocopying $n h r-49$ knockdown. Knockdown of $h p k-1$ also significantly reduced intestinal expression of the Pacs-2::gfp reporter in hypoxia (Figure 6C, D) and reduced expression of Pfmo-2::gfp in the $n h r-49(e t 13)$ background (Supplementary Figure 6A, B). We corroborated these data using qRT-PCR in wild-type worms and a $h p k-1$ (pk1393) mutant. The pk1393 allele deletes the majority of the kinase domain of $h p k-1$ and is a predicted molecular null allele (Raich et al., 2003). In hypoxia, the expression of both acs-2 and fmo-2 was significantly reduced by loss of $h p k-1$, phenocopying loss of $n h r-49$ (Figure 6E). Together, these data suggest that, like $n h r-49, h p k-1$ is required for upregulation of $f m o-2$ and $a c s-2$ in response to hypoxia.

To determine if $h p k-1$ is functionally required for worm survival in hypoxia, we assessed the ability of $h p k-1$ mutant embryos to survive hypoxia. Similar to $n h r-49$ mutant worms, only $45 \%$ of hpk-1 mutant embryos developed to L4 (wild-type worms 92\%; Figure 6F). We used epistasis analysis to test the hypothesis that $h p k-1$ acts in the $n h r-49$ pathway to coordinate a transcriptional response to hypoxia. We observed that the $n h r-49 ; h p k-1$ double null mutant showed similar survival (26\%) to each of the single null mutants, suggesting that these two genes act in the same hypoxia response pathway (Figure 6F). In contrast, the hif-1; hpk-1 double null mutant was significantly impaired $(<2 \%)$ compared to each of the single null mutants alone, consistent with the view that these two genes act in separate 
response pathways (Figure 6G). Each mutant showed normal development from embryo to L4 in

normoxia, indicating that the phenotypes observed were specifically due to the requirement of these

genes in hypoxia survival (Supplementary Figure 6C, D, Supplementary Table 1). Taken together,

these experiments show that $h p k-1$ is required for embryo survival in hypoxia, consistent with it

playing a role as an activator of the $n h r-49$-dependent response pathway.

\section{NHR-49 is regulated post-transcriptionally in hypoxia in an hpk-1-dependent fashion}

To test our hypothesis that HPK-1 activates NHR-49 in hypoxia, we examined whether NHR-

49 is induced by hypoxia and whether $h p k-1$ is involved in this regulation. NHR-49 and HPK-1 protein

levels are increased in response to tert-butyl hydroperoxide and/or heat shock, respectively, but mRNA

levels remain unchanged (Das et al., 2017; Goh et al., 2018). Similarly, we observed that $n h r-49$ and

hpk-1 mRNA levels were not increased upon exposure to hypoxia (Figure 7A). Consistent with this, a

following hypoxia exposure (Supplementary Figure 7A, B). These data show that transcription of neither $n h r-49$ nor $h p k-1$ are induced in hypoxia.

We considered the possibility that NHR-49 may be regulated post-transcriptionally. To assess

NHR-49 protein levels, we used the translational NHR-49::GFP reporter to measure the expression of

the fusion protein in response to hypoxia. Indeed, the whole worm NHR-49::GFP signal was modestly,

but significantly induced upon exposure to hypoxia (Figure 7B, C). Interestingly, while hpk-1 null 


\section{Discussion}

Animals, tissues, and cells must be able to rapidly, flexibly, and reversibly adapt to a plethora of stresses. Past studies have identified many stress response factors, often termed master regulators.

However, more recent studies indicate that stress response regulation requires the intricate interactions of multiple factors as part of networks that provide regulatory redundancy and flexibility. NHR-49 is a transcription factor that promotes longevity and development by regulating lipid metabolism and various stress responses (Chamoli et al., 2014; Dasgupta et al., 2020; Goh et al., 2018; Naim et al., 2020; Wani et al., 2020). Our data show that $n h r-49$ coordinates a new aspect of the transcriptional response to hypoxia. This pathway operates in parallel to, and independent of, the canonical hif-1 hypoxia response pathway. Besides $n h r-49$, it contains $n h r-67$ and $h p k-1$. The former acts during normoxia to repress NHR-49; however, during hypoxia, an increase in NHR-49 protein levels in turn represses $n h r-67$ levels, forming a feedback loop that may serve to reinforce NHR-49 activity. In contrast to $n h r-67$, the upstream kinase HPK-1 positively regulates the NHR-49 hypoxia response, as it is required to activate the NHR-49 regulated hypoxia response genes fmo- 2 and acs- 2 and to survive hypoxia. Downstream, NHR-49 induces autophagy genes, which are essential to promote hypoxia survival. Collectively, our experiments delineate a hif-1-independent hypoxia response pathway that contains distinct upstream and downstream components and is just as essential for hypoxia survival as is the hif-1 pathway (Figure 8).

\section{NHR-49 controls a novel hypoxia response pathway that is parallel to canonical HIF signaling} $n h r-49$ is required to induce fmo-2 in various stresses and infection models (Chamoli et al., 2014; Dasgupta et al., 2020; Goh et al., 2018; Naim et al., 2020; Wani et al., 2020). Similarly, HIF-1 regulates fmo-2 in several C. elegans longevity paradigms (Leiser et al., 2015), and fmo-2 is induced in hypoxia, specifically $0.1 \% \mathrm{O}_{2}$ exposure, in a hif-1-dependent manner (Leiser et al., 2015; Shen et al., 2005). This raised the possibility that hif- 1 also promoted fmo-2 expression in hypoxia $\left(0.5 \% \mathrm{O}_{2}\right)$ in $\mathrm{L} 4$ 
or older worms, and, more generally, that $n h r-49$ might act through hif-1 in the hypoxia response.

However, several lines of evidence support a model whereby HIF-1 and NHR-49 are core components of parallel, independent signaling networks (Figure 8). First, hif- 1 and $n h r-49$ interact genetically in hypoxia survival experiments, suggesting they work in separate genetic pathways (Figure 2A, B).

Second, our transcriptome analysis identified sets of genes that are regulated exclusively by HIF-1 or

NHR-49 in fmo-2 induction, also shows synthetic genetic interaction with hif-1, but not with $n h r-49$

(Figure $6 \mathrm{~F}, \mathrm{G}$ ). Collectively these data show that $n h r-49$ is a core part of a hypoxia response pathway that is independent of hif-1 signalling. In support of our study, a recent publication (Vozdek et al., 2018) showed that $n h r-49$ is required to induce the hif-1-independent hypoxia response gene comt-5 both in $0.5 \% \mathrm{O}_{2}$ and in a strain mutant for the kinase hir-1. In hypoxia, HIR-1 coordinates remodeling of the extracellular matrix independently of HIF-1 (Vozdek et al., 2018). Thus, although our RNA-seq results did not identify comt-5 as a target of NHR-49 in hypoxia, this study supports the idea of a hif-1independent hypoxia response pathway involving $n h r-49$.

\section{Homeodomain interacting protein kinases in hypoxia}

Our efforts to map additional components of the NHR-49 hypoxia response pathway, especially factors acting in concert with NHR-49, revealed $h p k-1$ (Figure 8). Homeodomain interacting protein kinases (HIPKs) are a family of nuclear serine/threonine kinase that can phosphorylate transcription factors (Rinaldo et al., 2007, 2008). The worm's only HIPK orthologue, $h p k-1$, regulates development and the response to DNA damage, heat shock, and dietary restriction (Berber et al., 2013, 2016; Das et al., 2017; Rinaldo et al., 2007). Here, we show that $h p k-1$ is an upstream regulator of the $n h r-49$ - 
425

ubiquitin ligase SIAH2 (Calzado et al., 2009). This degradation of HIPK2 is necessary, as the protein normally represses the expression of HIF-1 $\alpha$ by binding at its promoter in cell culture (Nardinocchi et al., 2009). In contrast, HIPK2 is induced in and required to protect cardiomyocytes from hypoxia/reoxygenation induced injury (Dang et al., 2020). This is consistent with our data and suggests that protecting cells from hypoxic injury may be a conserved role of HIPKs. Future experiments may reveal how HPK-1 is regulating NHR-49, perhaps examining direct phosphorylation and activation of the NHR-49 protein by HIPK-1.

\section{Paradoxical regulation of the $\beta$-oxidation gene acs- 2 by hypoxia}

Mitochondria consume cellular oxygen to produce energy and thus must adapt to limited oxygen availability. In particular, mitochondrial $\beta$-oxidation, the consumption of oxygen to catabolize fatty acids for energy production, is repressed in hypoxia in favour of anaerobic respiration. For example, the heart and skeletal muscle of mice and rats show decreased expression of key $\beta$-oxidation enzymes in acute hypoxia (Kennedy et al., 2001; Morash et al., 2013). In C. elegans, the acyl-CoA synthetase acs-2 is part of the mitochondrial $\beta$-oxidation pathway, where it functions in the first step to activate fatty acids. NHR- 49 activates acs- 2 expression during starvation, when $\beta$-oxidation is induced (M. R. Van Gilst et al., 2005). Considering this, acs-2 expression would be expected to be downregulated in hypoxia due to reduced $\beta$-oxidation. Paradoxically, however, we found that acs- 2 is strongly induced in hypoxia and that this regulation depends on $n h r-49$ (Figure 3C, Supplementary Figure 3A-C). Examination of other fatty acid $\beta$-oxidation enzymes in our RNA-seq data showed that

$a c s-2$ is the only enzyme induced. This suggests that, during hypoxia, ACS-2 is not feeding its product fatty acyl-CoA into the $\beta$-oxidation cycle, but perhaps produces fatty acyl-CoA for anabolic functions needed for survival to or recovery from low oxygen, such as phospholipid or triglyceride synthesis (reviewed in Tang et al., 2018). Similar functions have been observed in human macrophages, which, during hypoxia, decrease $\beta$-oxidation but increase triglyceride synthesis (Boström et al., 2006). 
In line with the repression of $\beta$-oxidation in hypoxia (Boström et al., 2006; Kennedy et al.,

2001; Morash et al., 2013), there is evidence supporting a HIF-dependent down-regulation of the

mammalian NHR-49 homolog PPAR $\alpha$, which promotes $\beta$-oxidation (Atherton et al., 2008). For

example, in human hepatocytes and in mouse liver sections, HIF-2 $\alpha$ accumulation in hypoxia directly

suppresses PPAR $\alpha$ expression (J. Chen et al., 2019). Additionally, HIF-1 $\alpha$ suppresses PPAR $\alpha$ protein

and mRNA levels during hypoxia in intestinal epithelial cells, and the PPARA promoter contains a

HIF-1 $\alpha$ DNA binding consensus motif, suggesting direct control of PPARA by HIF transcription

factors (Narravula \& Colgan, 2001).

Some evidence suggests alternative actions of PPAR $\alpha$. Knockdown of PPAR $\alpha$ attenuates the

ability of Phd1 (the homolog of C. elegans egl-9) knockout myofibers to successfully tolerate hypoxia

(Aragonés et al., 2008), suggesting that PPAR $\alpha$ is an important regulator of the hypoxia response

downstream of Phd1. Along these lines, PPAR $\alpha$ protein levels increase in the muscle of Phd1 knockout

mice (Aragonés et al., 2008) and following hypoxic exposure in mouse hearts (Morash et al., 2013).

Similarly, we show that NHR-49 protein levels increase in response to hypoxia (Figure 7B, C), and that

NHR-49 is a vital regulator of a hif-1-independent hypoxia response. Together, these data suggest that, similar to evidence from studies in mammalian systems, NHR-49 levels are increased and required in hypoxia, and may be regulating acs-2 for functions other than fatty acid $\beta$-oxidation.

\section{NHR-49 promotes autophagy activation to achieve hypoxia survival}

Damaged cellular components can be cleared via autophagy, a key process regulated by $n h r-49$

in hypoxia (Figure 3D, F). In mammals, PPAR $\alpha$ activates autophagy in response to various stresses, including in neurons to clear A $\beta$ in Alzheimer's disease (Luo et al., 2020), and in the liver during inflammation (Jiao et al., 2014) and starvation (J. M. Lee et al., 2014). Proper regulation of autophagy is also a requirement in hypoxic conditions. Knockdown or genetic mutation of various C. elegans 
475 elevated temperatures combined (Samokhvalov et al., 2008). Similarly, Zhang et al. found that

476 mitochondrial autophagy (mitophagy) is induced by hypoxia in mouse embryo fibroblasts. This process

477 requires expression of BNIP3 (Bcl-2/E1B $19 \mathrm{kDa}$-interacting protein 3), an autophagy inducer, which

478 is induced in a HIF-1-dependent manner (H. Zhang et al., 2008). In agreement with this, our RNA-seq

479 data showed a 3.8-fold induction of the C. elegans BNIP3 homolog dct-1 in hypoxia; however, this

480 induction was dependent on neither $n h r-49$ nor hif-1. The above study also found that the autophagy

481 genes Beclin-1 and Atg5 are induced and required for cell survival in hypoxia (H. Zhang et al., 2008).

482 Here, we show that the C. elegans ortholog of Beclin-1, bec-1, and the worm atg-7 and atg-10 genes,

483 which are involved in the completion of the autophagosome along with $\operatorname{atg}-5 / \operatorname{Atg} 5$, are required for

484 worm embryo survival to hypoxia in an $n h r-49$-dependent manner (Figure 3F). Interestingly, $h p k-1$

485 regulates autophagy in response to dietary restriction, as it is necessary to induce autophagosome

486 formation and autophagy gene expression (Das et al., 2017). $h p k-1$ may thus aid $n h r-49$ in the

487 regulation of autophagy during hypoxia as well.

488

\section{Cell non-autonomous functions of NHR-49 in hypoxia}

Cell non-autonomous regulation occurs in many pathways in C. elegans. For example, HIF-1

acts in neurons to induce fmo-2 expression in the intestine to promote longevity (Leiser et al., 2015).

NHR-49 is expressed in the intestine, neurons, muscle, and hypodermis (Ratnappan et al., 2014). Re-

expression of $n h r-49$ in any one of these tissues is sufficient to enhance worm survival upon infection

(Naim et al., 2020), but NHR-49 acts only in neurons to promote survival to P. aeruginosa (Naim et al.,

497 Surprisingly, we found that $n h r-49$ expression in any of the intestine, neurons, or hypodermis is 
499 non-autonomous fashion to execute its effects. Possibly, a signaling molecule whose synthesis is

500 promoted by NHR-49 activity in any tissue promotes organismal hypoxia adaptation.

501 In sum, we show here that NHR-49 regulates a novel hypoxia response pathway that is

502 independent of HIF-1 and controls an important transcriptional response for worm survival to hypoxia.

503 If the mammalian NHR-49 homologs PPAR $\alpha$ and HNF4 play similar roles in the cellular response to

504 hypoxia, our discovery could lead to the identification and development of new targets for drugs and

505 therapies for diseases exhibiting hypoxic conditions.

506 


\section{Materials and Methods}

\section{Nematode strains and growth conditions}

We cultured C. elegans strains using standard techniques on nematode growth media (NGM)

510 plates. To avoid background effects, each mutant was crossed into our lab N2 strain; original mutants

511 were backcrossed to N2 at least six times. E. coli OP50 was the food source in all experiments except

512 for RNAi experiments, where we used E. coli HT115. All experiments were carried out at $20^{\circ} \mathrm{C}$. Worm

513 strains used in this study are listed in Supplementary Table 6. For synchronized worm growths, we

514 isolated embryos by standard sodium hypochlorite treatment. Isolated embryos were allowed to hatch

515 overnight on unseeded NGM plates until the population reached a synchronized halted development at

516 L1 stage via short-term fasting (12-24 hr). Synchronized L1 stage larvae were then transferred to OP50

517 seeded plates and grown to the desired stage.

\section{Feeding RNA interference}

RNAi was performed on NGM plates supplemented with $25 \mu \mathrm{g} / \mathrm{ml}$ carbenicillin (BioBasic

CDJ469), 1 mM IPTG (Santa Cruz CAS 367-93-1), and $12.5 \mu \mathrm{g} / \mathrm{ml}$ tetracycline (BioBasic TB0504

(NGM-RNAi plates), and seeded with appropriate HT115 RNAi bacteria. The RNAi clones were from

the Ahringer library (Source BioScience) and were sequenced prior to use.

\section{RNA isolation and $q R T-P C R$ analysis}

Synchronized L1 worms were allowed to grow on OP50 plates for $48 \mathrm{hr}$ to L4 stage, then either

described (Goh et al., 2014). $2 \mu$ g total RNA was used to generate cDNA with Superscript II reverse 
expression)/(average reference expression) ratios of three normalization genes, act-1, tba-1, and $u b c-2$.

The reference sample was $E V(R N A i)$, wild-type, or $21 \% \mathrm{O}_{2}$, as appropriate. We used one-way ANOVA

to calculate statistical significance of gene expression changes and corrected for multiple comparisons

efficiency prior to use. All data originate from three or more independent biological repeats, and each

PCR reaction was conducted in technical triplicate. Sequences of qRT-PCR primers are listed in

\section{Analysis of fluorescent reporter lines via DIC and fluorescence microscopy}

To analyze fluorescence in reporter lines, egg lays were performed on NGM plates seeded with

to adulthood. Plates were then kept in $21 \% \mathrm{O}_{2}$ or transferred to $0.5 \% \mathrm{O}_{2}$ for $4 \mathrm{hr}$ and allowed to recover

for $1 \mathrm{hr}$ in normoxia before imaging. Worms were collected into M9 buffer containing 0.06\%

levamisole (Sigma L9756) for immobilization on 2\% (w/v) agarose pads for microscopy. We captured images on a CoolSnap HQ camera (Photometrics) attached to a Zeiss Axioplan 2 compound ImageJ software (https://imagej.nih.gov/ij/download.html), with fluorescence calculated by taking the difference of the background fluorescence from the mean intestinal or whole worm fluorescence. For 
whole worm fluorescence was measured. For each experiment, at least three independent trials were performed with a minimum of 30 worms per condition.

\section{NHR-49 transgenic strains}

To construct the Pnhr-49::nhr-49::gfp containing plasmid, a $6.6 \mathrm{~kb}$ genomic fragment of the

$n h r-49$ gene (including a $4.4 \mathrm{~kb}$ coding region covering all $n h r-49$ transcripts and a $2.2 \mathrm{~kb}$ promoter

region) was cloned into the GFP expression vector pPD95.77 (Addgene \#1495), as reported previously

562 (Ratnappan et al., 2014). For generating tissue-specific constructs, the $n h r-49$ promoter was replaced

with tissue-specific promoters using $S b f \mathrm{I}$ and $S a l \mathrm{I}$ restriction enzymes to create plasmids for expressing

NHR-49 in the muscle (Pmyo-3::nhr-49::gfp), intestine (Pgly-19::nhr-49::gfp), hypodermis (Pcol-

$12:: n h r-49: \because g f p$ ), and neurons (Prgef-1::nhr-49::gfp). $100 \mathrm{ng} / \mu \mathrm{l}$ of each plasmid was injected, along

with pharyngeal muscle-specific Pmyo-2::mCherry as a co-injection marker $(25 \mathrm{ng} / \mu \mathrm{l})$ into the $n h r$ -

49(nr2041) mutant strain using standard methods (Mello \& Fire, 1995). Strains were maintained by picking animals that were positive for both GFP and mCherry.

\section{Hypoxia sensitivity assays}

Hypoxic conditions were maintained using continuous flow chambers, as previously described

(Fawcett et al., 2012). Compressed gas tanks (5000 ppm $\mathrm{O}_{2}$ balanced with $\mathrm{N}_{2}$ ) were certified as standard to within 2\% of indicated concentration from Praxair Canada (Delta, BC). Oxygen flow was regulated using Aalborg rotameters (Aalborg Instruments and Controls, Inc., Orangeburg, NY, USA). Hypoxic chambers (and room air controls) were maintained in a $20^{\circ} \mathrm{C}$ incubator for the duration of the experiments.

For embryo survival assays, gravid first-day adult worms (picked as L4 the previous day) were allowed to lay eggs for 1-4 hr on plates seeded with $15 \mathrm{uL}$ OP50 or appropriate HT115 RNAi bacteria the previous day. Adults were removed, and eggs were exposed to $0.5 \% \mathrm{O}_{2}$ for $24 \mathrm{hr}$ or $48 \mathrm{hr}$. Animals 
were scored for developmental success (reached at least L4 stage) after being placed back into room air

581 for $65 \mathrm{hr}$ (following $24 \mathrm{hr}$ exposure) or $42 \mathrm{hr}$ (following $48 \mathrm{hr}$ exposure). For RNAi survival assays,

582 worms were grown for one generation from egg to adult on the appropriate HT115 RNAi bacteria

583 before their progeny was used for the egg lay.

$584 \quad$ For larval development assays, gravid adult worms (picked as L4 the previous day) were

585 allowed to lay eggs for $2 \mathrm{hr}$ and kept at $20^{\circ} \mathrm{C}$ for $13-17 \mathrm{hr}$ to allow hatching (egg lays for $n h r-$

$58649(n r 2041)$ strains with embryonic developmental delays were performed $2 \mathrm{hr}$ earlier to ensure

587 synchronization with wild-type worms). Freshly hatched L1 worms were transferred to plates seeded

588 with $15 \mu \mathrm{L}$ OP50 the previous day, and exposed to $0.5 \% \mathrm{O}_{2}$ for $48 \mathrm{hr}$. Animals were placed back into

589 room air and immediately scored for stage.

$590 \quad$ For all normoxia $\left(21 \% \mathrm{O}_{2}\right)$ comparison experiments, methods were as described above except

591 plates were kept in room air for the duration (instead of being exposed to $0.5 \% \mathrm{O}_{2}$ ).

592

\section{Hydrogen sulfide sensitivity assay}

594 Construction of $\mathrm{H}_{2} \mathrm{~S}$ chambers was as previously described (Fawcett et al., 2012; Miller \&

595 Roth, 2007). In short, 5000 ppm $\mathrm{H}_{2} \mathrm{~S}$ (balanced with $\mathrm{N}_{2}$ ) was diluted with room air to a final

596 concentration of $50 \mathrm{ppm}$ and monitored with a custom $\mathrm{H}_{2} \mathrm{~S}$ detector, as described (Miller \& Roth,

597 2007). Compressed gas mixtures were obtained from Airgas (Seattle, WA) and certified as standard to

598 within $2 \%$ of the indicated concentration. Survival assays were performed with 20 L4 animals picked

599 onto OP50 seeded plates. Plates were exposed to $50 \mathrm{ppm}_{2} \mathrm{~S}$ for $24 \mathrm{hr}$ in a $20^{\circ} \mathrm{C}$ incubator, then

600 returned to room air to score viability. Animals were scored 30 min after removal from $\mathrm{H}_{2} \mathrm{~S}$, and plates

601 with dead animals were re-examined after several hours to ensure animals had not reanimated.

602

603

RNA sequencing 
OP50 plates to $\mathrm{L} 4$ stage, then either kept in $21 \% \mathrm{O}_{2}$ or transferred to $0.5 \% \mathrm{O}_{2}$ for $3 \mathrm{hr}$. RNA was isolated from whole worms as described above. RNA integrity and quality were ascertained on a

BioAnalzyer. Construction of strand-specific mRNA sequencing libraries and sequencing (75bp PET)

on an Illumina HiSeq 2500 machine was done at the Sequencing Services facility of the Genome

610 (https://www.bcgsc.ca/services/sequencing-services). The raw FASTQ reads obtained from the facility 611 were trimmed using Trimmomatic version 0.36 (Bolger et al., 2014) with parameters LEADING:3

TRAILING:3 SLIDINGWINDOW:4:15 MINLEN:36. Next, the trimmed reads were aligned to the

614 (https://www.ncbi.nlm.nih.gov/assembly/GCF 000002985.6/) using Salmon version 0.9.1 (Patro et al., 615 2017) with parameters -1 A -p 8 --gcBias. Then, transcript-level read counts were imported into R and 616 summed into gene-level read counts using tximport (Soneson et al., 2015). Genes not expressed at a 617 level greater than 1 count per million (CPM) reads in at least three of the samples were excluded from 618 further analysis. The gene-level read counts were normalized using the trimmed mean of M-values 619 (TMM) in edgeR (Robinson et al., 2010) to adjust samples for differences in library size. Differential expression analysis was performed using the quasi-likelihood F-test with the generalized linear model (GLM) approach in edgeR (Robinson et al., 2010). Differentially expressed genes (DEGs) were defined as those with at least two-fold difference between two individual groups at a false discovery rate $($ FDR $)<0.05$. RNA-seq data have been deposited at NCBI Gene Expression Omnibus (https://www.ncbi.nlm.nih.gov/geo/) under the record GSE166788. 


\section{Acknowledgements}

We thank the Taubert, Miller, and Ghazi labs for comments on the manuscript. Some strains

632

were provided by the CGC, which is funded by NIH Office of Research Infrastructure Programs (P40

633 OD010440). Grant support was from The Canadian Institutes of Health Research (CIHR; PJT-153199

634 to ST), the Natural Sciences and Engineering Research Council of Canada (NSERC; RGPIN-2018-

63505133 to ST), the Cancer Research Society (CRS; to ST), and the National Institutes of Health (NIH;

636 R01AG051659 to AG, R01AG044378 to DM). KRSD was supported by NSERC CGS-M, NSERC

637 CGS-D, and BCCHR scholarships, and ST by a Canada Research Chair.

638

639 Competing interests

640 The authors do not declare any competing interests.

641 
642

\section{3}

644

645

646

647

648

649

650

651

652

653

654

655

656

657

658

659

660

661

662

663

664

665

\section{References}

Albadari, N., Deng, S., \& Li, W. (2019). The transcriptional factors HIF-1 and HIF-2 and their novel inhibitors in cancer therapy. Expert Opinion on Drug Discovery, 14(7), 667-682. https://doi.org/10.1080/17460441.2019.1613370

Aragonés, J., Schneider, M., Van Geyte, K., Fraisl, P., Dresselaers, T., Mazzone, M., Dirkx, R., Zacchigna, S., Lemieux, H., Jeoung, N. H., Lambrechts, D., Bishop, T., Lafuste, P., Diez-Juan, A., Harten, S. K., Van Noten, P., De Bock, K., Willam, C., Tjwa, M., ... Carmeliet, P. (2008).

Deficiency or inhibition of oxygen sensor Phd1 induces hypoxia tolerance by reprogramming basal metabolism. Nature Genetics, 40(2), 170-180. https://doi.org/10.1038/ng.2007.62

Atherton, H. J., Jones, O. A. H., Malik, S., Miska, E. A., \& Griffin, J. L. (2008). A comparative metabolomic study of NHR-49 in Caenorhabditis elegans and PPAR- $\alpha$ in the mouse. FEBS Letters, 582(12), 1661-1666. https://doi.org/10.1016/j.febslet.2008.04.020

Berber, S., Llamosas, E., Thaivalappil, P., Boag, P. R., Crossley, M., \& Nicholas, H. R. (2013). Homeodomain interacting protein kinase (HPK-1) is required in the soma for robust germline proliferation in C. elegans: HPK-1 Promotes Germline Proliferation. Developmental Dynamics, 242(11), 1250-1261. https://doi.org/10.1002/dvdy.24023

Berber, S., Wood, M., Llamosas, E., Thaivalappil, P., Lee, K., Liao, B. M., Chew, Y. L., Rhodes, A., Yucel, D., Crossley, M., \& Nicholas, H. R. (2016). Homeodomain-Interacting Protein Kinase (HPK-1) regulates stress responses and ageing in C. elegans. Scientific Reports, 6(1), 19582. https://doi.org/10.1038/srep19582

Bishop, T., Lau, K. W., Epstein, A. C. R., Kim, S. K., Jiang, M., O’Rourke, D., Pugh, C. W., Gleadle, J. M., Taylor, M. S., Hodgkin, J., \& Ratcliffe, P. J. (2004). Genetic analysis of pathways regulated by the von Hippel-Lindau tumor suppressor in Caenorhabditis elegans. PLoS Biology, 2(10), e289. https://doi.org/10.1371/journal.pbio.0020289 
666

667

668

Bolger, A. M., Lohse, M., \& Usadel, B. (2014). Trimmomatic: A flexible trimmer for Illumina sequence data. Bioinformatics, 30(15), 2114-2120. https://doi.org/10.1093/bioinformatics/btu170

Boström, P., Magnusson, B., Svensson, P.-A., Wiklund, O., Borén, J., Carlsson, L. M. S., Ståhlman, M., Olofsson, S.-O., \& Hultén, L. M. (2006). Hypoxia Converts Human Macrophages Into Triglyceride-Loaded Foam Cells. Arteriosclerosis, Thrombosis, and Vascular Biology, 26(8), 1871-1876. https://doi.org/10.1161/01.ATV.0000229665.78997.0b

Brenner, S. (1974). The genetics of Caenorhabditis elegans. Genetics, 77(1), 71-94.

Budde, M. W., \& Roth, M. B. (2010). Hydrogen sulfide increases hypoxia-inducible factor-1 activity independently of von Hippel-Lindau tumor suppressor-1 in C. elegans. Molecular Biology of the Cell, 21(1), 212-217. https://doi.org/10.1091/mbc.e09-03-0199

Burkewitz, K., Morantte, I., Weir, H. J. M., Yeo, R., Zhang, Y., Huynh, F. K., Ilkayeva, O. R., Hirschey, M. D., Grant, A. R., \& Mair, W. B. (2015). Neuronal CRTC-1 governs systemic mitochondrial metabolism and lifespan via a catecholamine signal. Cell, 160(5), 842-855. https://doi.org/10.1016/j.cell.2015.02.004

Calzado, M. A., de la Vega, L., Möller, A., Bowtell, D. D. L., \& Schmitz, M. L. (2009). An inducible autoregulatory loop between HIPK2 and Siah2 at the apex of the hypoxic response. Nature Cell Biology, 11(1), 85-91. https://doi.org/10.1038/ncb1816

Chamoli, M., Singh, A., Malik, Y., \& Mukhopadhyay, A. (2014). A novel kinase regulates dietary restriction-mediated longevity in Caenorhabditis elegans. Aging Cell, 13(4), 641-655. https://doi.org/10.1111/acel.12218

Chapin, H. C., Okada, M., Merz, A. J., \& Miller, D. L. (2015). Tissue-specific autophagy responses to aging and stress in C. elegans. Aging, 7(6), 419-434. https://doi.org/10.18632/aging.100765

Chen, J., Chen, J., Fu, H., Li, Y., Wang, L., Luo, S., \& Lu, H. (2019). Hypoxia exacerbates nonalcoholic fatty liver disease via the HIF-2 $\alpha /$ PPAR $\alpha$ pathway. American Journal of 
bioRxiv preprint doi: https://doi.org/10.1101/2021.02.24.432575; this version posted February 24, 2021. The copyright holder for this preprint (which was not certified by peer review) is the author/funder. All rights reserved. No reuse allowed without permission.

Doering et al. Hypoxia

691

692

693

694

695

696

Physiology-Endocrinology and Metabolism, 317(4), E710-E722.

https://doi.org/10.1152/ajpendo.00052.2019

Chen, W., Hill, H., Christie, A., Kim, M. S., Holloman, E., Pavia-Jimenez, A., Homayoun, F., Ma, Y., Patel, N., Yell, P., Hao, G., Yousuf, Q., Joyce, A., Pedrosa, I., Geiger, H., Zhang, H., Chang, J., Gardner, K. H., Bruick, R. K., ... Brugarolas, J. (2016). Targeting renal cell carcinoma with a HIF-2 antagonist. Nature, 539(7627), 112-117. https://doi.org/10.1038/nature19796

Cho, H., Du, X., Rizzi, J. P., Liberzon, E., Chakraborty, A. A., Gao, W., Carvo, I., Signoretti, S., Bruick, R. K., Josey, J. A., Wallace, E. M., \& Kaelin, W. G. (2016). On-target efficacy of a HIF-2 $\alpha$ antagonist in preclinical kidney cancer models. Nature, 539(7627), 107-111. https://doi.org/10.1038/nature19795

Choudhry, H., \& Harris, A. L. (2018). Advances in Hypoxia-Inducible Factor Biology. Cell Metabolism, 27(2), 281-298. https://doi.org/10.1016/j.cmet.2017.10.005

Dang, X., Zhang, R., Peng, Z., Qin, Y., Sun, J., Niu, Z., \& Pei, H. (2020). HIPK2 overexpression relieves hypoxia/reoxygenation-induced apoptosis and oxidative damage of cardiomyocytes through enhancement of the Nrf2/ARE signaling pathway. Chemico-Biological Interactions, 316, 108922. https://doi.org/10.1016/j.cbi.2019.108922

Das, R., Melo, J. A., Thondamal, M., Morton, E. A., Cornwell, A. B., Crick, B., Kim, J. H., Swartz, E. W., Lamitina, T., Douglas, P. M., \& Samuelson, A. V. (2017). The homeodomain-interacting protein kinase HPK-1 preserves protein homeostasis and longevity through master regulatory control of the HSF-1 chaperone network and TORC1-restricted autophagy in Caenorhabditis elegans. PLOS Genetics, 13(10), e1007038. https://doi.org/10.1371/journal.pgen.1007038

Dasgupta, M., Shashikanth, M., Gupta, A., Sandhu, A., De, A., Javed, S., \& Singh, V. (2020). NHR-49 Transcription Factor Regulates Immunometabolic Response and Survival of Caenorhabditis elegans during Enterococcus faecalis Infection. Infection and Immunity, 88(8). https://doi.org/10.1128/IAI.00130-20 
716

Epstein, A. C., Gleadle, J. M., McNeill, L. A., Hewitson, K. S., O’Rourke, J., Mole, D. R., Mukherji, M., Metzen, E., Wilson, M. I., Dhanda, A., Tian, Y. M., Masson, N., Hamilton, D. L., Jaakkola, P., Barstead, R., Hodgkin, J., Maxwell, P. H., Pugh, C. W., Schofield, C. J., \& Ratcliffe, P. J. (2001). C. elegans EGL-9 and mammalian homologs define a family of dioxygenases that regulate HIF by prolyl hydroxylation. Cell, 107(1), 43-54. https://doi.org/10.1016/s0092$8674(01) 00507-4$

Fallah, J., \& Rini, B. I. (2019). HIF Inhibitors: Status of Current Clinical Development. Current Oncology Reports, 21(1), 6. https://doi.org/10.1007/s11912-019-0752-z

Fawcett, E. M., Horsman, J. W., \& Miller, D. L. (2012). Creating defined gaseous environments to study the effects of hypoxia on C. elegans. Journal of Visualized Experiments: JoVE, 65, e4088. https://doi.org/10.3791/4088

Fernandes, J. S., \& Sternberg, P. W. (2007). The tailless Ortholog nhr-67 Regulates Patterning of Gene Expression and Morphogenesis in the C. elegans Vulva. PLoS Genetics, 3(4), e69. https://doi.org/10.1371/journal.pgen.0030069

Gissendanner, C. R., Crossgrove, K., Kraus, K. A., Maina, C. V., \& Sluder, A. E. (2004). Expression and function of conserved nuclear receptor genes in Caenorhabditis elegans. Developmental Biology, 266(2), 399-416. https://doi.org/10.1016/j.ydbio.2003.10.014

Goh, G. Y. S., Martelli, K. L., Parhar, K. S., Kwong, A. W. L., Wong, M. A., Mah, A., Hou, N. S., \& Taubert, S. (2014). The conserved Mediator subunit MDT-15 is required for oxidative stress responses in Caenorhabditis elegans. Aging Cell, 13(1), 70-79. https://doi.org/10.1111/acel.12154

Goh, G. Y. S., Winter, J. J., Bhanshali, F., Doering, K. R. S., Lai, R., Lee, K., Veal, E. A., \& Taubert, S. (2018). NHR-49/HNF4 integrates regulation of fatty acid metabolism with a protective transcriptional response to oxidative stress and fasting. Aging Cell, 17(3), e12743. https://doi.org/10.1111/acel.12743 
741

Jiang, H., Guo, R., \& Powell-Coffman, J. A. (2001). The Caenorhabditis elegans hif-1 gene encodes a bHLH-PAS protein that is required for adaptation to hypoxia. Proceedings of the National Academy of Sciences of the United States of America, 98(14), 7916-7921. https://doi.org/10.1073/pnas.141234698

Jiao, M., Ren, F., Zhou, L., Zhang, X., Zhang, L., Wen, T., Wei, L., Wang, X., Shi, H., Bai, L., Zhang, X., Zheng, S., Zhang, J., Chen, Y., Han, Y., Zhao, C., \& Duan, Z. (2014). Peroxisome proliferator-activated receptor $\alpha$ activation attenuates the inflammatory response to protect the liver from acute failure by promoting the autophagy pathway. Cell Death \& Disease, 5, e1397. https://doi.org/10.1038/cddis.2014.361

Kaelin, W. G. (2008). The von Hippel-Lindau tumour suppressor protein: O2 sensing and cancer. Nature Reviews. Cancer, 8(11), 865-873. https://doi.org/10.1038/nrc2502

Keith, B., \& Simon, M. C. (2007). Hypoxia-inducible factors, stem cells, and cancer. Cell, 129(3), 465-472. https://doi.org/10.1016/j.cell.2007.04.019

Kennedy, S. L., Stanley, W. C., Panchal, A. R., \& Mazzeo, R. S. (2001). Alterations in enzymes involved in fat metabolism after acute and chronic altitude exposure. Journal of Applied Physiology (Bethesda, Md.: 1985), 90(1), 17-22. https://doi.org/10.1152/jappl.2001.90.1.17

Lee, J. M., Wagner, M., Xiao, R., Kim, K. H., Feng, D., Lazar, M. A., \& Moore, D. D. (2014). Nutrient-sensing nuclear receptors coordinate autophagy. Nature, 516(7529), 112-115. https://doi.org/10.1038/nature13961

Lee, K., Goh, G. Y. S., Wong, M. A., Klassen, T. L., \& Taubert, S. (2016). Gain-of-Function Alleles in Caenorhabditis elegans Nuclear Hormone Receptor nhr-49 Are Functionally Distinct. PloS One, 11(9), e0162708. https://doi.org/10.1371/journal.pone.0162708

Lee, P., Chandel, N. S., \& Simon, M. C. (2020). Cellular adaptation to hypoxia through hypoxia inducible factors and beyond. Nature Reviews. Molecular Cell Biology, 21(5), 268-283. https://doi.org/10.1038/s41580-020-0227-y 
Leiser, S. F., Miller, H., Rossner, R., Fletcher, M., Leonard, A., Primitivo, M., Rintala, N., Ramos, F. J., Miller, D. L., \& Kaeberlein, M. (2015). Cell nonautonomous activation of flavin-containing monooxygenase promotes longevity and health span. Science (New York, N.Y.), 350(6266), 1375-1378. https://doi.org/10.1126/science.aac9257

Li, L., Rose, P., \& Moore, P. K. (2011). Hydrogen sulfide and cell signaling. Annual Review of Pharmacology and Toxicology, 51, 169-187. https://doi.org/10.1146/annurev-pharmtox-

Li, M., \& Kim, W. Y. (2011). Two sides to every story: The HIF-dependent and HIF-independent functions of pVHL. Journal of Cellular and Molecular Medicine, 15(2), 187-195. https://doi.org/10.1111/j.1582-4934.2010.01238.x

Li, Y., Padmanabha, D., Gentile, L. B., Dumur, C. I., Beckstead, R. B., \& Baker, K. D. (2013). HIFand non-HIF-regulated hypoxic responses require the estrogen-related receptor in Drosophila melanogaster. PLoS Genetics, 9(1), e1003230. https://doi.org/10.1371/journal.pgen.1003230

Liu, L. X., Spoerke, J. M., Mulligan, E. L., Chen, J., Reardon, B., Westlund, B., Sun, L., Abel, K., Armstrong, B., Hardiman, G., King, J., McCague, L., Basson, M., Clover, R., \& Johnson, C. D. (1999). High-throughput isolation of Caenorhabditis elegans deletion mutants. Genome Research, 9(9), 859-867. https://doi.org/10.1101/gr.9.9.859

Luo, R., Su, L.-Y., Li, G., Yang, J., Liu, Q., Yang, L.-X., Zhang, D.-F., Zhou, H., Xu, M., Fan, Y., Li, J., \& Yao, Y.-G. (2020). Activation of PPARA-mediated autophagy reduces Alzheimer diseaselike pathology and cognitive decline in a murine model. Autophagy, 16(1), 52-69. https://doi.org/10.1080/15548627.2019.1596488

Mello, C., \& Fire, A. (1995). DNA transformation. Methods in Cell Biology, 48, 451-482.

Miller, D. L., Budde, M. W., \& Roth, M. B. (2011). HIF-1 and SKN-1 coordinate the transcriptional response to hydrogen sulfide in Caenorhabditis elegans. PloS One, 6(9), e25476. https://doi.org/10.1371/journal.pone.0025476 
bioRxiv preprint doi: https://doi.org/10.1101/2021.02.24.432575; this version posted February 24, 2021. The copyright holder for this preprint (which was not certified by peer review) is the author/funder. All rights reserved. No reuse allowed without permission.

Doering et al. Hypoxia

791

792

793

794

795

796

797

798

799

800

801

802

803

804

805

806

807

808

809

810

811

812

813

814

815

Miller, D. L., \& Roth, M. B. (2007). Hydrogen sulfide increases thermotolerance and lifespan in Caenorhabditis elegans. Proceedings of the National Academy of Sciences of the United States of America, 104(51), 20618-20622. https://doi.org/10.1073/pnas.0710191104

Morash, A. J., Kotwica, A. O., \& Murray, A. J. (2013). Tissue-specific changes in fatty acid oxidation in hypoxic heart and skeletal muscle. American Journal of Physiology. Regulatory, Integrative and Comparative Physiology, 305(5), R534-541. https://doi.org/10.1152/ajpregu.00510.2012

Naim, N., Amrit, F. R., Ratnappan, R., DelBuono, N., Loose, J. A., \& Ghazi, A. (2020). NHR-49 Acts in Distinct Tissues to Promote Longevity versus Innate Immunity [Preprint]. Molecular Biology. https://doi.org/10.1101/2020.09.11.290452

Nardinocchi, L., Puca, R., Guidolin, D., Belloni, A. S., Bossi, G., Michiels, C., Sacchi, A., Onisto, M., \& D’Orazi, G. (2009). Transcriptional regulation of hypoxia-inducible factor 1alpha by HIPK2 suggests a novel mechanism to restrain tumor growth. Biochimica Et Biophysica Acta, 1793(2), 368-377. https://doi.org/10.1016/j.bbamcr.2008.10.013

Narravula, S., \& Colgan, S. P. (2001). Hypoxia-Inducible Factor 1-Mediated Inhibition of Peroxisome Proliferator-Activated Receptor a Expression During Hypoxia. The Journal of Immunology, 166(12), 7543-7548. https://doi.org/10.4049/jimmunol.166.12.7543

Nystul, T. G., \& Roth, M. B. (2004). Carbon monoxide-induced suspended animation protects against hypoxic damage in Caenorhabditis elegans. Proceedings of the National Academy of Sciences of the United States of America, 101(24), 9133-9136. https://doi.org/10.1073/pnas.0403312101

Padmanabha, D., Padilla, P. A., You, Y.-J., \& Baker, K. D. (2015). A HIF-independent mediator of transcriptional responses to oxygen deprivation in Caenorhabditis elegans. Genetics, 199(3), 739-748. https://doi.org/10.1534/genetics.114.173989

Pathare, P. P., Lin, A., Bornfeldt, K. E., Taubert, S., \& Van Gilst, M. R. (2012). Coordinate regulation of lipid metabolism by novel nuclear receptor partnerships. PLoS Genetics, 8(4), e1002645. https://doi.org/10.1371/journal.pgen.1002645 
Patro, R., Duggal, G., Love, M. I., Irizarry, R. A., \& Kingsford, C. (2017). Salmon: Fast and bias-aware quantification of transcript expression using dual-phase inference. Nature Methods, 14(4), 417. https://doi.org/10.1038/nmeth.4197

Powell-Coffman, J. A. (2010). Hypoxia signaling and resistance in C. elegans. Trends in Endocrinology and Metabolism: TEM, 21(7), 435-440. https://doi.org/10.1016/j.tem.2010.02.006

\section{2} 823 activated autophagy accelerates degradation of SQSTM1/p62. Oncogene, 28(3), 334-344. https://doi.org/10.1038/onc.2008.392

Raich, W. B., Moorman, C., Lacefield, C. O., Lehrer, J., Bartsch, D., Plasterk, R. H. A., Kandel, E. R., \& Hobert, O. (2003). Characterization of Caenorhabditis elegans homologs of the Down syndrome candidate gene DYRK1A. Genetics, 163(2), 571-580.

Rankin, E. B., \& Giaccia, A. J. (2016). Hypoxic control of metastasis. Science (New York, N.Y.), 352(6282), 175-180. https://doi.org/10.1126/science.aaf4405

Ratnappan, R., Amrit, F. R. G., Chen, S.-W., Gill, H., Holden, K., Ward, J., Yamamoto, K. R., Olsen, C. P., \& Ghazi, A. (2014). Germline signals deploy NHR-49 to modulate fatty-acid $\beta$-oxidation and desaturation in somatic tissues of C. elegans. PLoS Genetics, 10(12), e1004829. https://doi.org/10.1371/journal.pgen.1004829

Reece-Hoyes, J. S., Pons, C., Diallo, A., Mori, A., Shrestha, S., Kadreppa, S., Nelson, J., DiPrima, S., Dricot, A., Lajoie, B. R., Ribeiro, P. S. M., Weirauch, M. T., Hill, D. E., Hughes, T. R., Myers, C. L., \& Walhout, A. J. M. (2013). Extensive Rewiring and Complex Evolutionary Dynamics in a C. elegans Multiparameter Transcription Factor Network. Molecular Cell, 51(1), 116-127. https://doi.org/10.1016/j.molcel.2013.05.018 
Rinaldo, C., Prodosmo, A., Siepi, F., \& Soddu, S. (2007). HIPK2: A multitalented partner for transcription factors in DNA damage response and development. Biochemistry and Cell Biology = Biochimie Et Biologie Cellulaire, 85(4), 411-418. https://doi.org/10.1139/O07-071

Rinaldo, C., Siepi, F., Prodosmo, A., \& Soddu, S. (2008). HIPKs: Jack of all trades in basic nuclear activities. Biochimica Et Biophysica Acta, 1783(11), 2124-2129. https://doi.org/10.1016/j.bbamcr.2008.06.006

\section{5}

846

Samokhvalov, V., Scott, B. A., \& Crowder, C. M. (2008). Autophagy protects against hypoxic injury in C. elegans. Autophagy, 4(8), 1034-1041. https://doi.org/10.4161/auto.6994

Schito, L., \& Semenza, G. L. (2016). Hypoxia-Inducible Factors: Master Regulators of Cancer Progression. Trends in Cancer, 2(12), 758-770. https://doi.org/10.1016/j.trecan.2016.10.016

Shen, C., Nettleton, D., Jiang, M., Kim, S. K., \& Powell-Coffman, J. A. (2005). Roles of the HIF-1 hypoxia-inducible factor during hypoxia response in Caenorhabditis elegans. The Journal of Biological Chemistry, 280(21), 20580-20588. https://doi.org/10.1074/jbc.M501894200

Soneson, C., Love, M. I., \& Robinson, M. D. (2015). Differential analyses for RNA-seq: Transcriptlevel estimates improve gene-level inferences. F1000Research, 4. https://doi.org/10.12688/f1000research.7563.2

Tang, Y., Zhou, J., Hooi, S. C., Jiang, Y.-M., \& Lu, G.-D. (2018). Fatty acid activation in carcinogenesis and cancer development: Essential roles of long-chain acyl-CoA synthetases. Oncology Letters, 16(2), 1390-1396. https://doi.org/10.3892/ol.2018.8843

Van Gilst, M. R., Hadjivassiliou, H., \& Yamamoto, K. R. (2005). From The Cover: A Caenorhabditis elegans nutrient response system partially dependent on nuclear receptor NHR-49. Proceedings 
863

864 865 866 867 868 869 870 871 872

of the National Academy of Sciences, 102(38), 13496-13501. https://doi.org/10.1073/pnas.0506234102

Van Gilst, Marc R., Hadjivassiliou, H., Jolly, A., \& Yamamoto, K. R. (2005). Nuclear hormone receptor NHR-49 controls fat consumption and fatty acid composition in C. elegans. PLoS Biology, 3(2), e53. https://doi.org/10.1371/journal.pbio.0030053

Verghese, E., Schocken, J., Jacob, S., Wimer, A. M., Royce, R., Nesmith, J. E., Baer, G. M., Clever, S., McCain, E., Lakowski, B., \& Wightman, B. (2011). The tailless ortholog nhr-67 functions in the development of the C. elegans ventral uterus. Developmental Biology, 356(2), 516-528. https://doi.org/10.1016/j.ydbio.2011.06.007

Vozdek, R., Long, Y., \& Ma, D. K. (2018). The receptor tyrosine kinase HIR-1 coordinates HIFindependent responses to hypoxia and extracellular matrix injury. Science Signaling, 11(550). https://doi.org/10.1126/scisignal.aat0138

Wani, K. A., Goswamy, D., Taubert, S., Ratnappan, R., Ghazi, A., \& Irazoqui, J. E. (2020). NHR49/PPAR- $\alpha$ and HLH-30/TFEB promote C. elegans host defense via a flavin-containing monooxygenase [Preprint]. Microbiology. https://doi.org/10.1101/2020.09.03.282087

Zhang, H., Bosch-Marce, M., Shimoda, L. A., Tan, Y. S., Baek, J. H., Wesley, J. B., Gonzalez, F. J., \& Semenza, G. L. (2008). Mitochondrial autophagy is an HIF-1-dependent adaptive metabolic response to hypoxia. The Journal of Biological Chemistry, 283(16), 10892-10903. https://doi.org/10.1074/jbc.M800102200

Zhang, J., Bakheet, R., Parhar, R. S., Huang, C.-H., Hussain, M. M., Pan, X., Siddiqui, S. S., \& Hashmi, S. (2011). Regulation of Fat Storage and Reproduction by Krüppel-Like Transcription Factor KLF3 and Fat-Associated Genes in Caenorhabditis elegans. Journal of Molecular Biology, 411(3), 537-553. https://doi.org/10.1016/j.jmb.2011.06.011 
bioRxiv preprint doi: https://doi.org/10.1101/2021.02.24.432575; this version posted February 24, 2021. The copyright holder for this preprint (which was not certified by peer review) is the author/funder. All rights reserved. No reuse allowed without permission.

Doering et al. Hypoxia

886 Zhang, T., Suo, C., Zheng, C., \& Zhang, H. (2019). Hypoxia and Metabolism in Metastasis. Advances

887 in Experimental Medicine and Biology, 1136, 87-95. https://doi.org/10.1007/978-3-030-12734-

888

3

889

890 


\section{Figure Legends}

\section{Figure 1. $n h r-49$ regulates fmo-2 induction following exposure to hypoxia.}

(A) The graph indicates fold changes of mRNA levels (relative to unexposed wild-type) in L4 wild-type, $n h r-49(n r 2041)$, and hif-1(ia4) worms exposed to room air $\left(21 \% \mathrm{O}_{2}\right)$ or $0.5 \% \mathrm{O}_{2}$ for $3 \mathrm{hr}(\mathrm{n}$ $=5$ ). ${ }^{* * *} \mathrm{p}<0.05,0.01$ (ordinary one-way ANOVA corrected for multiple comparisons using the adult worms in room air or following $4 \mathrm{hr}$ exposure to $0.5 \% \mathrm{O}_{2}$ and $1 \mathrm{hr}$ recovery in $21 \% \mathrm{O}_{2}$. (C) The graph shows the quantification of intestinal GFP levels in Pfmo-2::gfp and Pfmo-2::gfp;nhr49(nr2041) worms following $4 \mathrm{hr}$ exposure to $0.5 \% \mathrm{O}_{2}$ and $1 \mathrm{hr}$ recovery in $21 \% \mathrm{O}_{2}$ (three repeats totalling $>30$ individual worms per genotype). $* *, * * * * p<0.01,0.0001$ (ordinary one-way ANOVA corrected for multiple comparisons using the Tukey method). WT = wild-type.

902

Figure 2. $n h r-49$ and $h i f-1$ act in separate hypoxia response pathways at two stages of the

worm life cycle.

(A) The graph shows average population survival of wild-type, nhr-49(nr2041), hif-1(ia4), and nhr-49(nr2041); hif-1(ia4) worm embryos exposed for $24 \mathrm{hr}$ to $0.5 \% \mathrm{O}_{2}$ and then allowed to recover at $21 \% \mathrm{O}_{2}$ for $65 \mathrm{hr}$, counted as ability to reach at least the L4 stage (five repeats totalling $>100$ individual worms per genotype). $* * * * \mathrm{p}<0.0001$ vs. wild-type worms, $\perp \mathrm{p}<0.05$ vs. $n h r-49$ (nr2041); hif-1(ia4) (ordinary one-way ANOVA corrected for multiple comparisons using the Tukey method). (B) The graph shows average developmental success of wild-type, $n h r-49(n r 2041)$, hif-1(ia4), and nhr49(nr2041); hif-1(ia4) larval worms following $48 \mathrm{hr}$ exposure to $0.5 \% \mathrm{O}_{2}$ from L1 stage (four repeats totalling $>60$ individual worms per genotype). ${ }^{* * *}, * * * * \mathrm{p}<0.001,0.0001$ percent L4 or older vs. wildtype worms (ordinary one-way ANOVA corrected for multiple comparisons using the Tukey method). (C) The graph shows average population survival of wild-type, nhr-49(nr2041), and hif-1(ia4) L4 worms following $24 \mathrm{hr}$ exposure to $50 \mathrm{ppm}$ hydrogen sulfide (three repeats totalling 60 individual 

multiple comparisons using the Tukey method). n.s. = not significant, WT = wild-type.

\section{Figure 3. RNA-seq reveals an $n h r-49-d e p e n d e n t$ transcriptional program in hypoxia.}

(A, B) Venn diagrams show the overlap of sets of hypoxia $\left(0.5 \% \mathrm{O}_{2}\right.$; vs. normoxia $\left.21 \% \mathrm{O}_{2}\right)$

regulated genes identified in differential expression analysis comparing wild-type, $n h r-49(n r 2041)$, and hif-1(ia4) worms. Numbers indicate the number of significantly differentially expressed genes that are upregulated (A) and downregulated (B) at least two-fold. (C) Heatmap of the expression levels of the

83 genes which are significantly induced over two-fold in $21 \% \mathrm{O}_{2}$ vs. $0.5 \% \mathrm{O}_{2}$ in wild-type and hif-

1(ia4) worms, but not in $n h r-49(n r 2041)$, i.e. $n h r-49$-dependent hypoxia response genes. Genes along

the $y$-axis are colored in each repeat based on their z-scores of the log2-transformed Counts Per Million

(CPM) plus 1. Notable genes are highlighted. (D) Network view of the enriched functional categories and hif-1(ia4) worms, but not in $n h r-49(n r 2041)$. Edges represent significant gene overlap as defined by a Jaccard Coefficient larger than or equal to $25 \%$. The dot size reflects the number of genes in each functional category; colour intensity reflects statistical significance (-log10 p-value). (E) The graph shows the average population survival of wild-type, $n h r-49(n r 2041)$, fmo-2(ok2147), acs-2(ok2457), and fmo-2(ok2147); acs-2(ok2457) worm embryos following $24 \mathrm{hr}$ exposure to $0.5 \% \mathrm{O}_{2}$, then allowed to recover at $21 \% \mathrm{O}_{2}$ for $65 \mathrm{hr}$, and counted as ability to reach at least $\mathrm{L} 4$ stage (five or more repeats totalling $>100$ individual worms per strain). ${ }^{* * * *} \mathrm{p}<0.0001$ vs. wild-type worms. Comparison of single mutants to fmo-2(ok2147); acs-2(ok2457) not significant (ordinary one-way ANOVA corrected for multiple comparisons using the Tukey method). (F) The graph shows the average population survival of second generation wild-type and $n h r-49(n r 2041)$ worm embryos fed EV, nhr-49, atg-10, atg-7, bec9391 , or epg-3 RNAi, followed by $24 \mathrm{hr}$ exposure to $0.5 \% \mathrm{O}_{2}$ and recovery at $21 \% \mathrm{O}_{2}$ for $65 \mathrm{hr}$, and 940 counted as ability to reach at least L4 stage (three or more repeats totalling $>100$ individual worms per 
strain). $* * *, * * *, * * * * \mathrm{p}<0.05,0.01,0.001,0.0001$ vs. followed by worms fed $E V(R N A i)$ (ordinary

942 one-way ANOVA corrected for multiple comparisons using the Tukey method). n.s. = not significant,

943 WT $=$ wild-type.

944

945

\section{Figure 4. $n h r-49$ is sufficient to promote survival in hypoxia and induce some hypoxia}

response genes.

(A) The graph shows the average population survival of wild-type, $n h r-49(n r 2041)$, and $n h r-$

49 (et13) worm embryos following $48 \mathrm{hr}$ exposure to $0.5 \% \mathrm{O}_{2}$, then allowed to recover at $21 \% \mathrm{O}_{2}$ for

$42 \mathrm{hr}$, and counted as ability to reach at least L4 stage (five repeats totalling $>100$ individual worms per

950

strain). ${ }^{*} \mathrm{p}<0.05$ vs. wild-type worms, $\perp \perp \perp \mathrm{p}<0.001$ vs. $n h r-49$ (et13) worms (ordinary one-way

951

ANOVA corrected for multiple comparisons using the Tukey method). (B) The graph shows average

population survival of $n h r-49$ tissue specific rescue worm embryos following $24 \mathrm{hr}$ exposure to $0.5 \%$

$\mathrm{O}_{2}$, then allowed to recover at $21 \% \mathrm{O}_{2}$ for $65 \mathrm{hr}$, and counted as ability to reach at least L4 stage. Pglp-

19::nhr-49::gfp for intestine, Pcol-12::nhr-49::gfp for hypodermis, Prgef-1::nhr-49::gfp for neurons,

and Pnhr-49::nhr-49::gfp for endogenous (four or more repeats totalling $>50$ individual worms per

strain). ${ }^{*} \mathrm{p}<0.05$ vs. matching non-GFP siblings. (C) The graph shows fold changes of mRNA levels

(relative to wild-type) in L4 nhr-49(et13) worms $(\mathrm{n}=3) . * * * * \mathrm{p}<0.05,0.001$ vs. wild-type worms

(ordinary one-way ANOVA corrected for multiple comparisons using the Tukey method). WT = wildtype.

Figure 5. $n h r-67$ is a negative regulator of the $n h r-49$-dependent hypoxia response

pathway.

(A) The graph shows average transcript levels in counts per million (CPM) of $n h r-67 \mathrm{mRNA}$ in 
method). (B-E) Representative micrographs and quantification of intestinal GFP levels in Pfmo-2::gfp and Pfmo-2::gfp;nhr-49(nr2041) (B, C) and Pacs-2::gfp and Pacs-2::gfp;nhr-49(nr2041) (D, E) adult worms fed EV RNAi or $n h r-67 \mathrm{RNAi}$ following $4 \mathrm{hr}$ exposure to $0.5 \% \mathrm{O}_{2}$ and $1 \mathrm{hr}$ recovery in $21 \% \mathrm{O}_{2}$ (three repeats totalling $>30$ individual worms per strain). $* * * *, * * * * p<0.05,0.001,0.0001$ (ordinary one-way ANOVA corrected for multiple comparisons using the Tukey method). (F) Representative micrographs show Pnhr-49::nhr-49::gfp adult worms fed EV, nhr-49, or $n h r-67$ RNAi following 4 hr exposure to $0.5 \% \mathrm{O}_{2}$ and $1 \mathrm{hr}$ recovery in $21 \% \mathrm{O}_{2}$. (G) The graph shows quantification of whole worm

$0.5 \% \mathrm{O}_{2}$ and $1 \mathrm{hr}$ recovery in $21 \% \mathrm{O}_{2}$ (three or more repeats totalling $>30$ individual worms per strain). method). n.s. = not significant, WT $=$ wild-type.

pathway.

(A-D) Representative micrographs and quantification of intestinal GFP levels in Pfmo-2::gfp

(A, B) and Pacs-2::gfp (C, D) adult worms fed $E V$, nhr-49, hif-1, or hpk-1 RNAi following 4 hr 982 exposure to $0.5 \% \mathrm{O}_{2}$ and $1 \mathrm{hr}$ recovery in $21 \% \mathrm{O}_{2}(3$ or more repeats totalling $>30$ individual worms per strain). ${ }^{* *}, * * *, * * * * \mathrm{p}<0.01,0.001,0.0001 \mathrm{vs.} E V(R N A i)$ (ordinary one-way ANOVA corrected for multiple comparisons using the Tukey method). (E) The graph shows fold changes of mRNA levels in 985 L4 wild-type, $n h r-49(n r 2041)$, and $h p k-1$ (pk1393) worms exposed to $0.5 \% \mathrm{O}_{2}$ for $3 \mathrm{hr}(\mathrm{n}=4)$. **,*** $\mathrm{p}$ $986<0.01,0.001$ (ordinary one-way ANOVA corrected for multiple comparisons using the Tukey 987 method). (F) The graph shows average population survival of wild-type, $n h r-49(n r 2041)$, hpk988 1(pk1393), and $n h r-49(n r 2041) ; h p k-1$ (pk1393) worm embryos following $24 \mathrm{hr}$ exposure to $0.5 \% \mathrm{O}_{2}$, 989 then allowed to recover at $21 \% \mathrm{O}_{2}$ for $65 \mathrm{hr}$, and counted as ability to reach at least L4 stage (4 repeats 990 totalling $>100$ individual worms per strain). $* * *, * * * * \mathrm{p}<0.001,0.0001$ vs. wild-type worms. 
991 Comparison of single mutants to $n h r-49(n r 2041)$; $h p k-1(p k 1393)$ not significant (ordinary one-way

992 ANOVA corrected for multiple comparisons using the Tukey method). (G) The graph shows average

993 population survival of wild-type, hif-1(ia4), hpk-1(pk1393), and hif-1(ia4); hpk-1(pk1393) worm

994 embryos following $24 \mathrm{hr}$ exposure to $0.5 \% \mathrm{O}_{2}$, then allowed to recover at $21 \% \mathrm{O}_{2}$ for $65 \mathrm{hr}$, and 995 counted as ability to reach at least L4 stage (four repeats totalling $>100$ individual worms per strain). 996

$* * * * \mathrm{p}<0.0001$ vs. wild-type worms, $\perp \perp \perp \mathrm{p}<0.001$ vs. hif-1(ia4); hpk-1(pk1393) (ordinary one-way ANOVA corrected for multiple comparisons using the Tukey method). n.s. = not significant, WT = wild-type.

999

Figure 7. NHR-49 is induced in hypoxia in an $h p k-1-d e p e n d e n t$ fashion.

(A) The graph shows the average fold changes of mRNA levels (relative to unexposed wild-

type wild-type) in L4 wild-type worms exposed to $0.5 \% \mathrm{O}_{2}$ for $3 \mathrm{hr}(\mathrm{n}=4$; ordinary one-way ANOVA

corrected for multiple comparisons using the Tukey method). (B) Representative micrographs show

Pnhr-49::nhr-49::gfp and Pnhr-49::nhr-49::gfp; hpk-1(pk1393) adult worms following 4 hr exposure

to $0.5 \% \mathrm{O}_{2}$ and $1 \mathrm{hr}$ recovery in $21 \% \mathrm{O}_{2}$. (C) The graph shows the quantification of whole worm GFP

levels in Pnhr-49::nhr-49::gfp and Pnhr-49::nhr-49::gfp;hpk-1(pk1393) worms following 4 hr

exposure to $0.5 \% \mathrm{O}_{2}$ and $1 \mathrm{hr}$ recovery in $21 \% \mathrm{O}_{2}$ (three repeats totalling $>30$ individual worms per

strain). $* * * * \mathrm{p}<0.0001$ (ordinary one-way ANOVA corrected for multiple comparisons using the

Tukey method). n.s. = not significant, WT = wild-type.

\section{Figure 8. Model of the new NHR-49 hypoxia response pathway and its interaction with}

\section{HIF-1 signaling.}

The proposed model of how NHR-49 regulates a new, hif-1-independent hypoxia response.

1014 During normoxia, the transcription factor NHR-67 negatively regulates NHR-49. However, during 
bioRxiv preprint doi: https://doi.org/10.1101/2021.02.24.432575; this version posted February 24, 2021. The copyright holder for this preprint (which was not certified by peer review) is the author/funder. All rights reserved. No reuse allowed without permission.

Doering et al. Hypoxia

1016 NHR-49 to activate its downstream hypoxia response target genes, including fmo-2, acs-2, and

$\lfloor 017$ autophagy genes, whose induction is required for worm survival to hypoxia. (Figure created with

1018 Biorender.com, Toronto, ON, Canada).

1019 
bioRxiv preprint doi: https://doi.org/10.1101/2021.02.24.432575; this version posted February 24, 2021. The copyright holder for this preprint (which was not certified by peer review) is the author/funder. All rights reserved. No reuse allowed without permission.

Figure 1

A

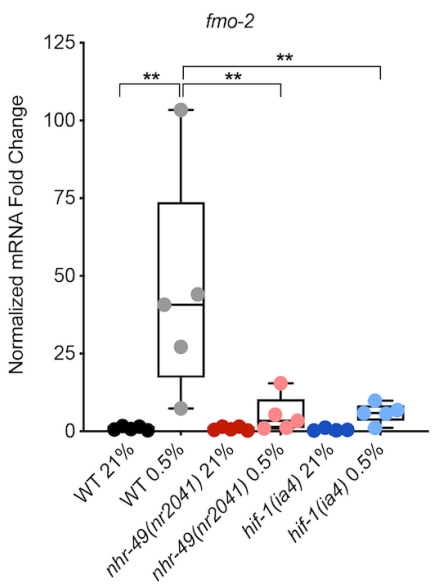

C

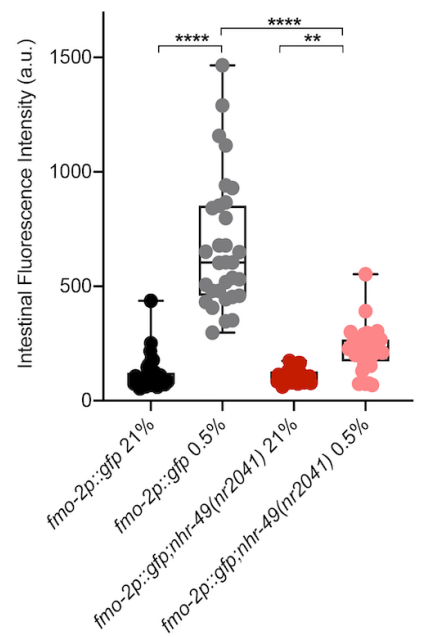

B

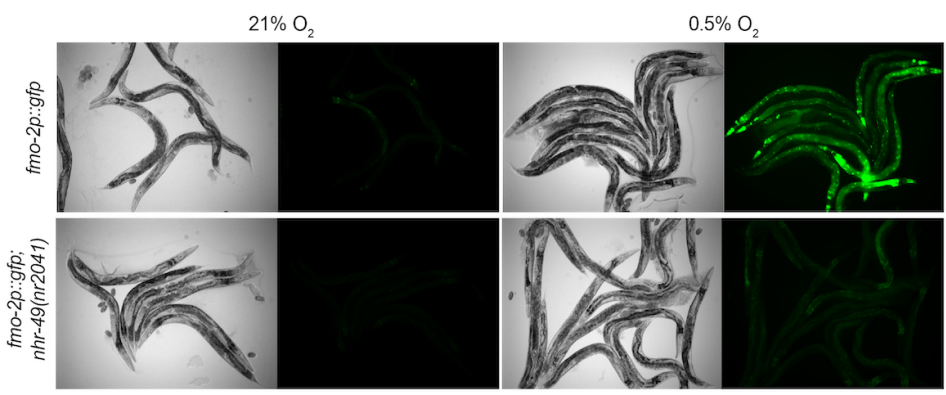


bioRxiv preprint doi: https://doi.org/10.1101/2021.02.24.432575; this version posted February 24, 2021. The copyright holder for this preprint (which was not certified by peer review) is the author/funder. All rights reserved. No reuse allowed without permission.

Figure 2

A

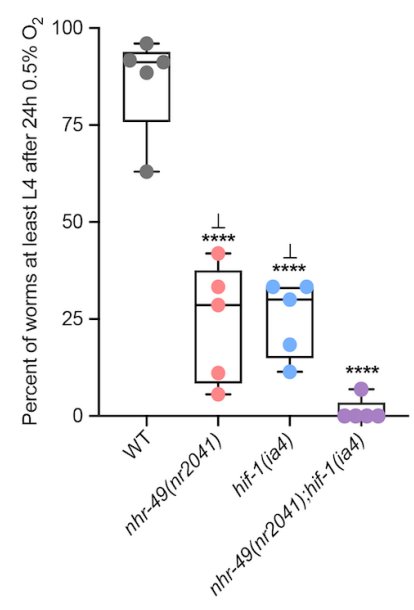

B

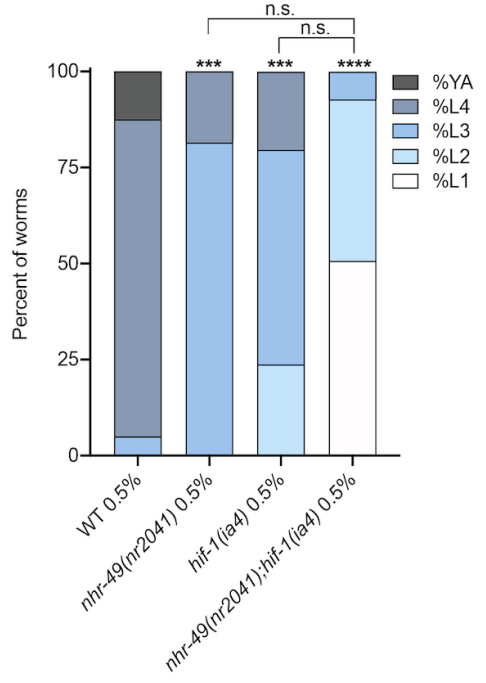

C

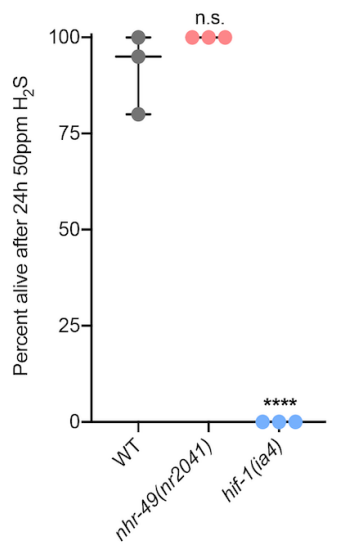




\section{Figure 3}

A

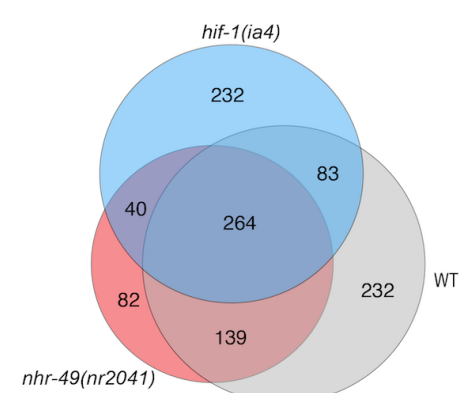

D

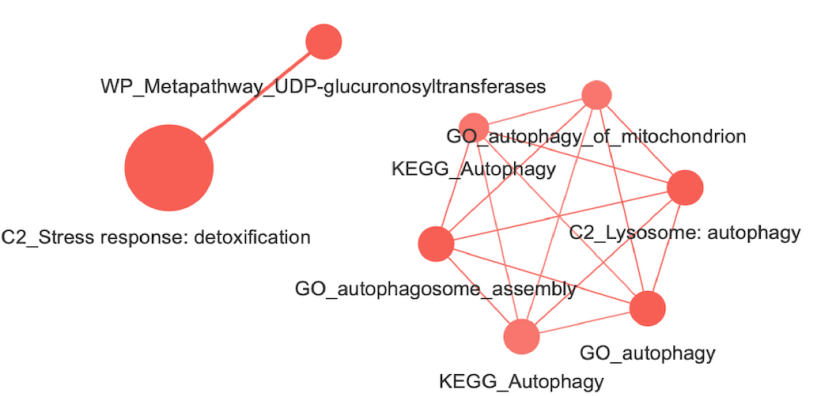

B

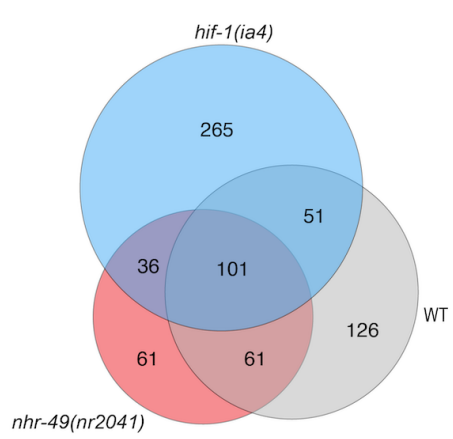

E
C acs-2:

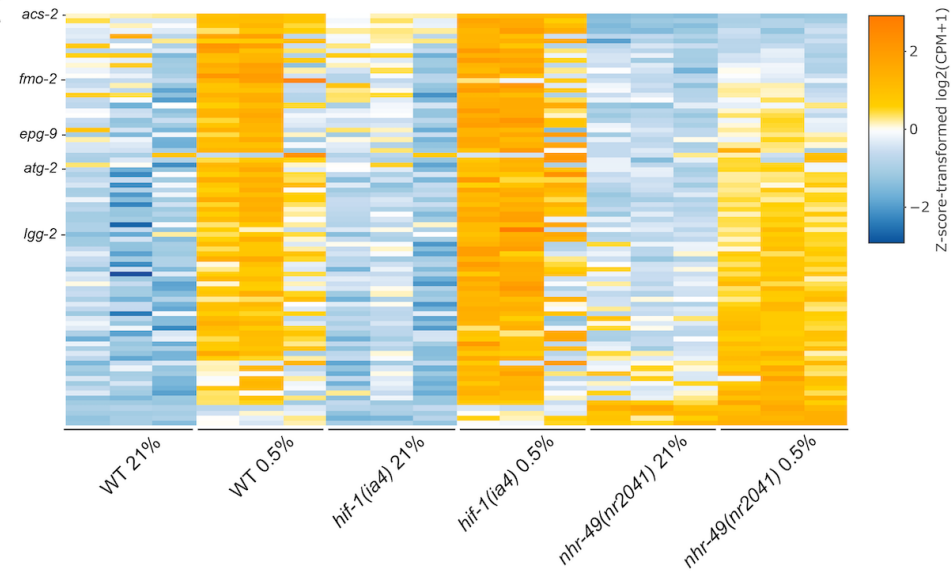

F

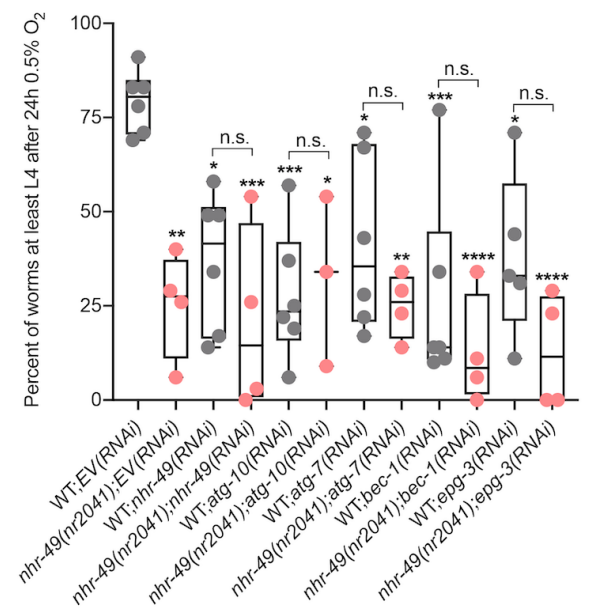


Figure 5

A

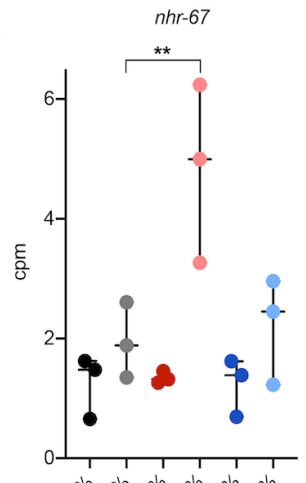

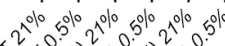

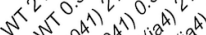

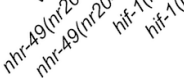

B
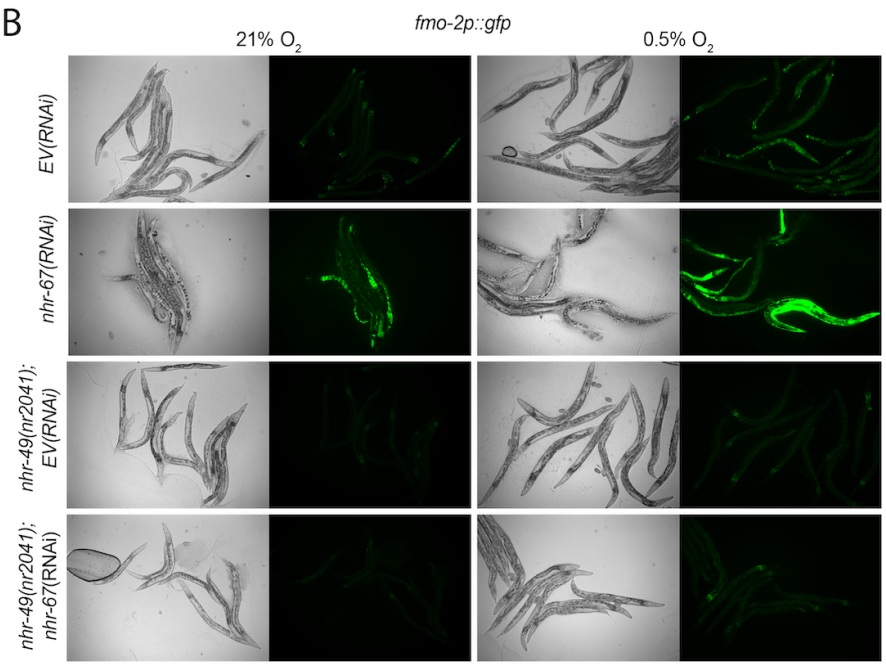

D

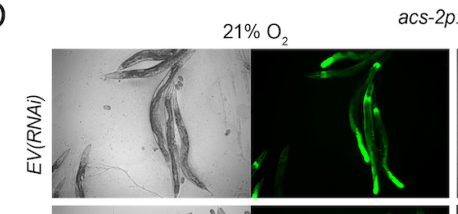

acs-2p::gfp
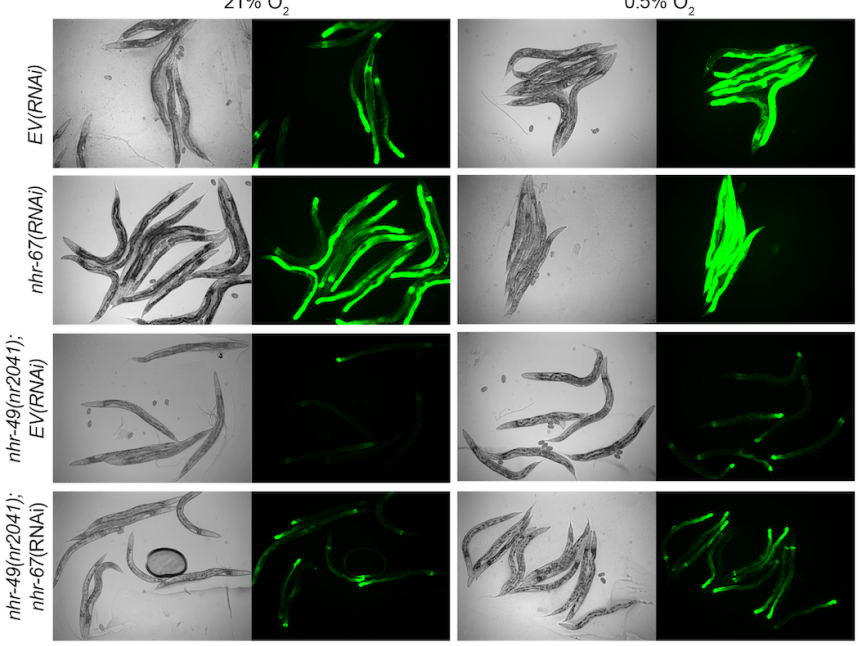

$\mathrm{F}$
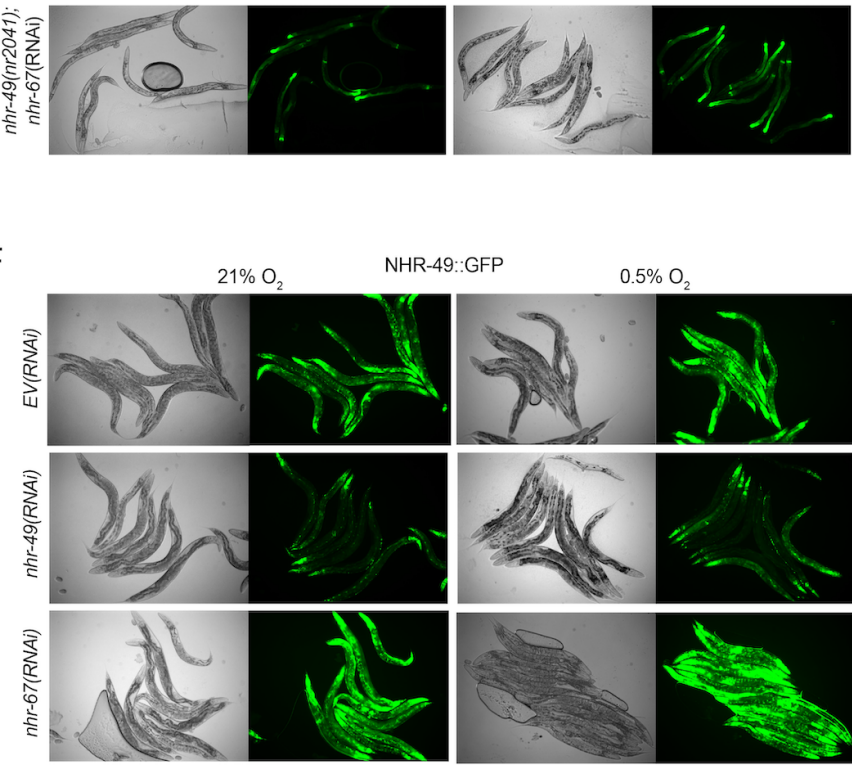

C
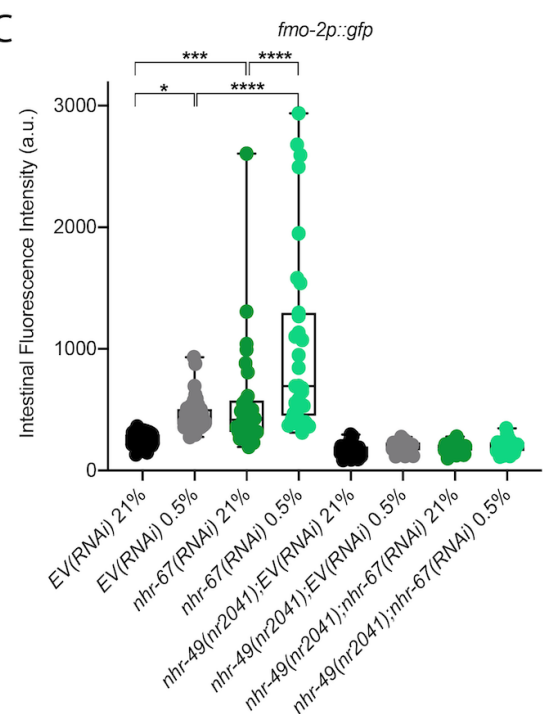

$\mathrm{E}$

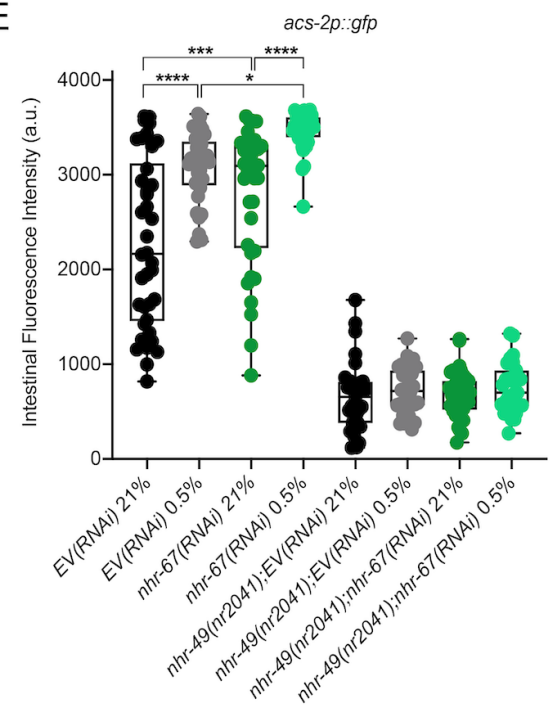

G

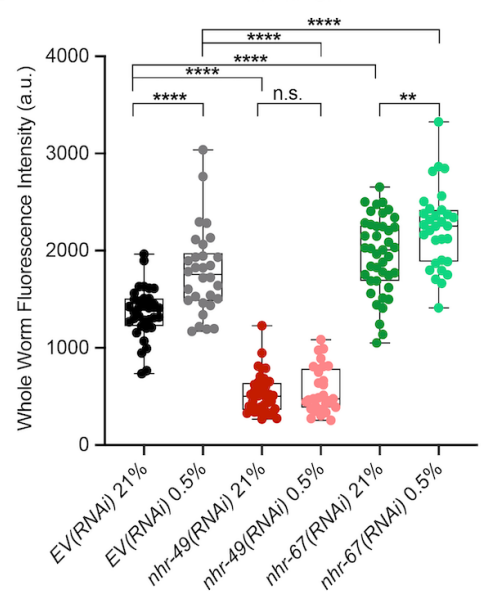


bioRxiv preprint doi: https://doi.org/10.1101/2021.02.24.432575; this version posted February 24, 2021. The copyright holder for this preprint (which was not certified by peer review) is the author/funder. All rights reserved. No reuse allowed without permission.

Figure 4

A

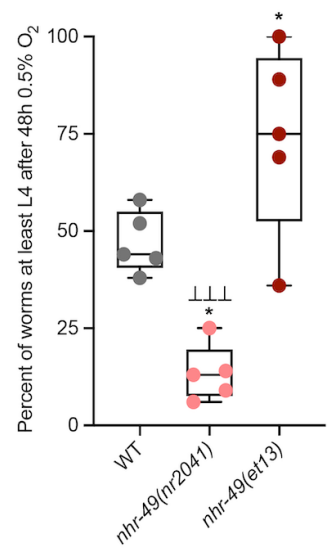

B

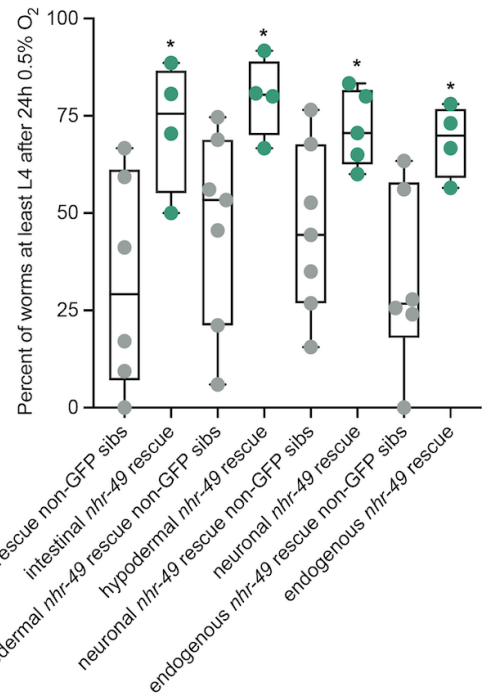

C

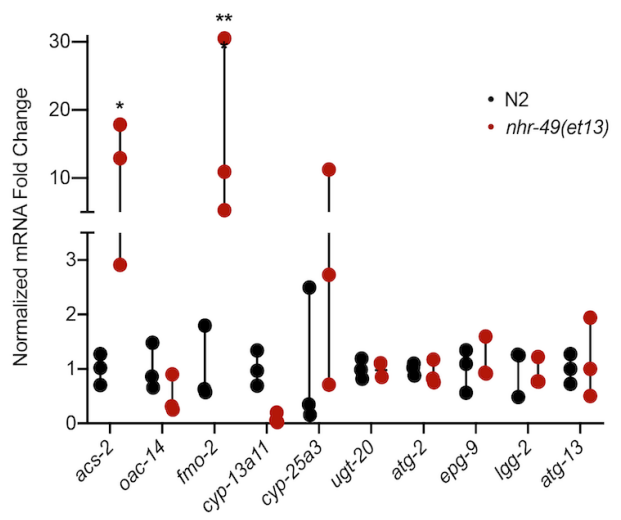


bioRxiv preprint doi: https://doi.org/10.1101/2021.02.24.432575; this version posted February 24, 2021. The copyright holder for this preprint (which was not certified by peer review) is the author/funder. All rights reserved. No reuse allowed without permission.

Figure 6
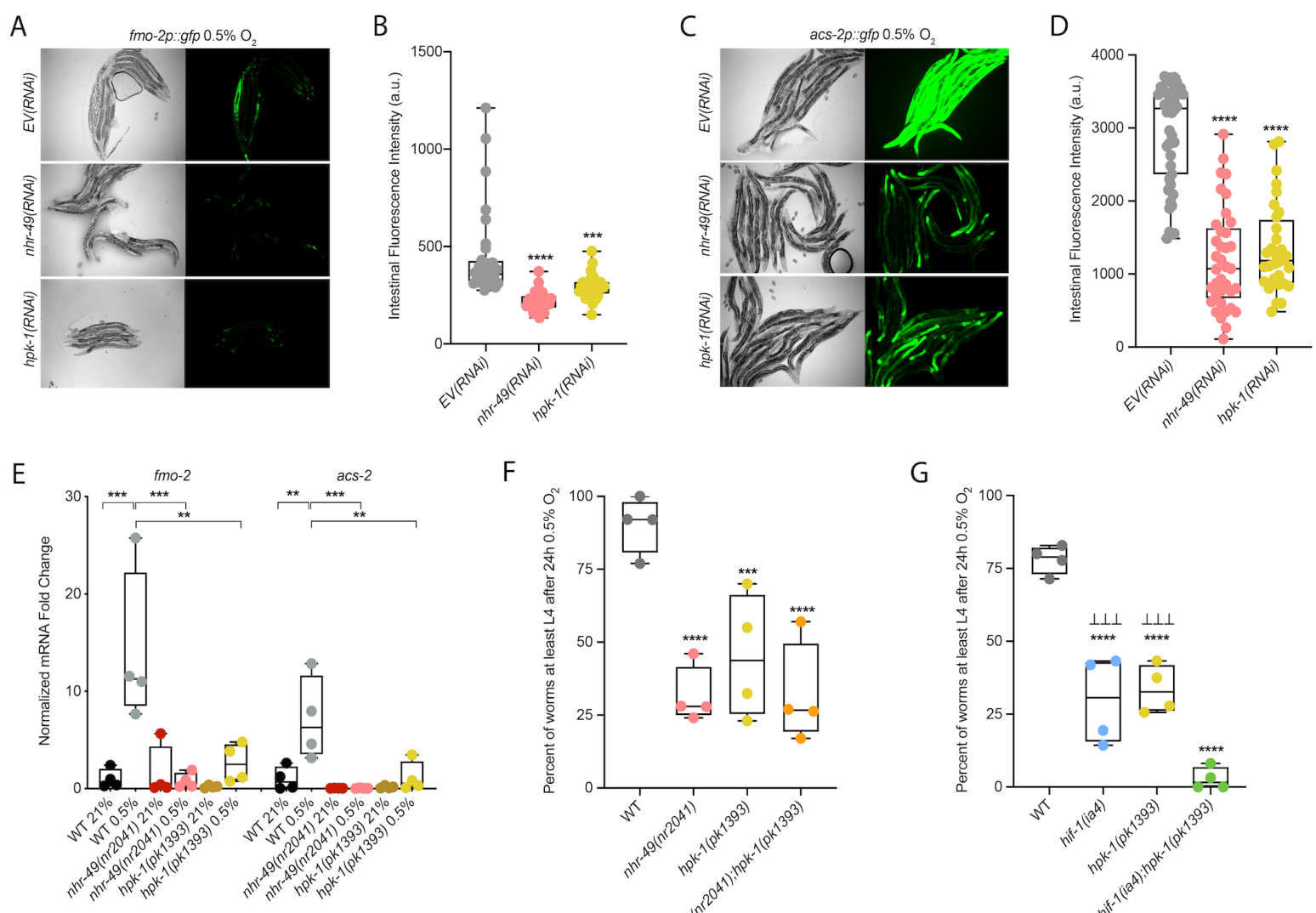

$\mathrm{F}$

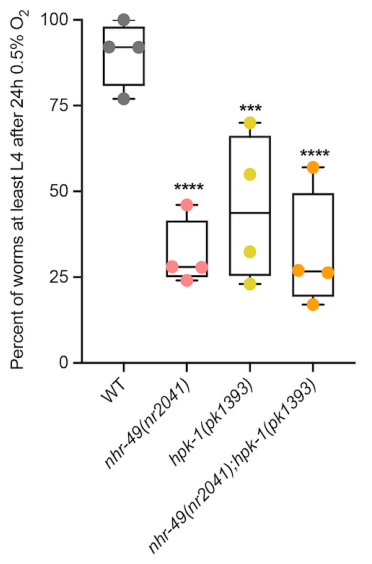

G

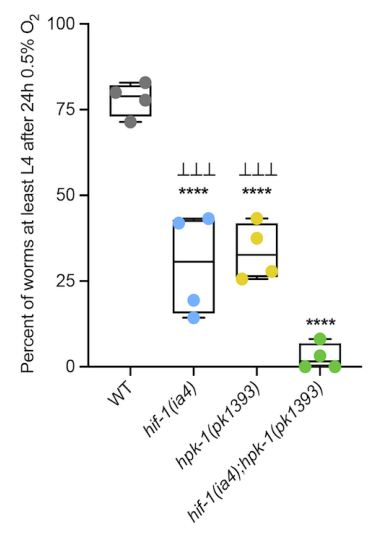


bioRxiv preprint doi: https://doi.org/10.1101/2021.02.24.432575; this version posted February 24, 2021. The copyright holder for this preprint (which was not certified by peer review) is the author/funder. All rights reserved. No reuse allowed without permission.

Figure 7

A

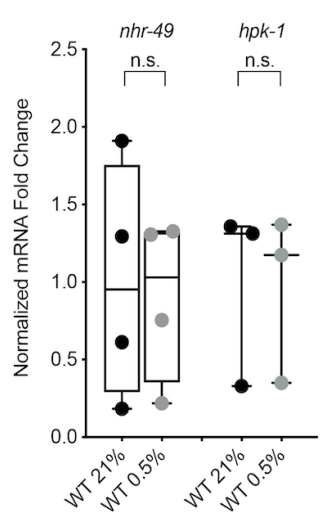

B

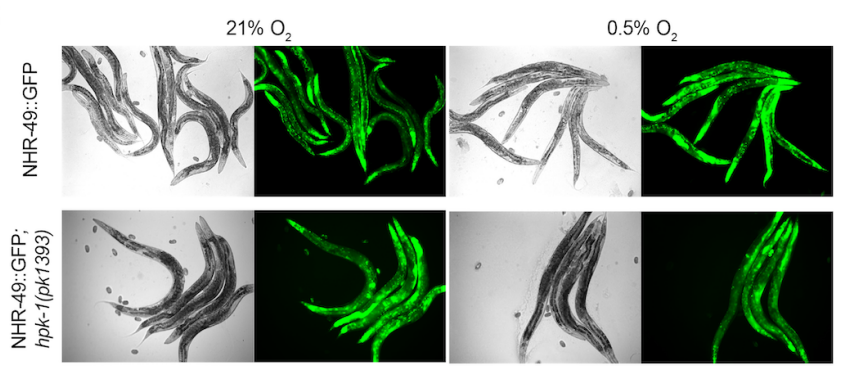

C

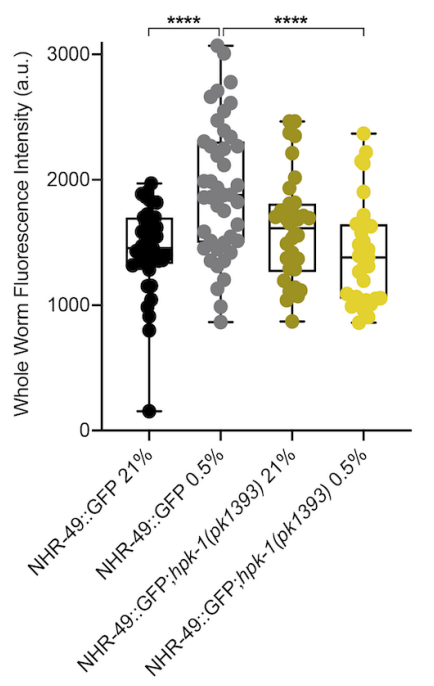


bioRxiv preprint doi: https://doi.org/10.1101/2021.02.24.432575; this version posted February 24, 2021. The copyright holder for this preprint Figure 8 (which was not certified by peer review) is the author/funder. All rights reserved. No reuse allowed without permission.

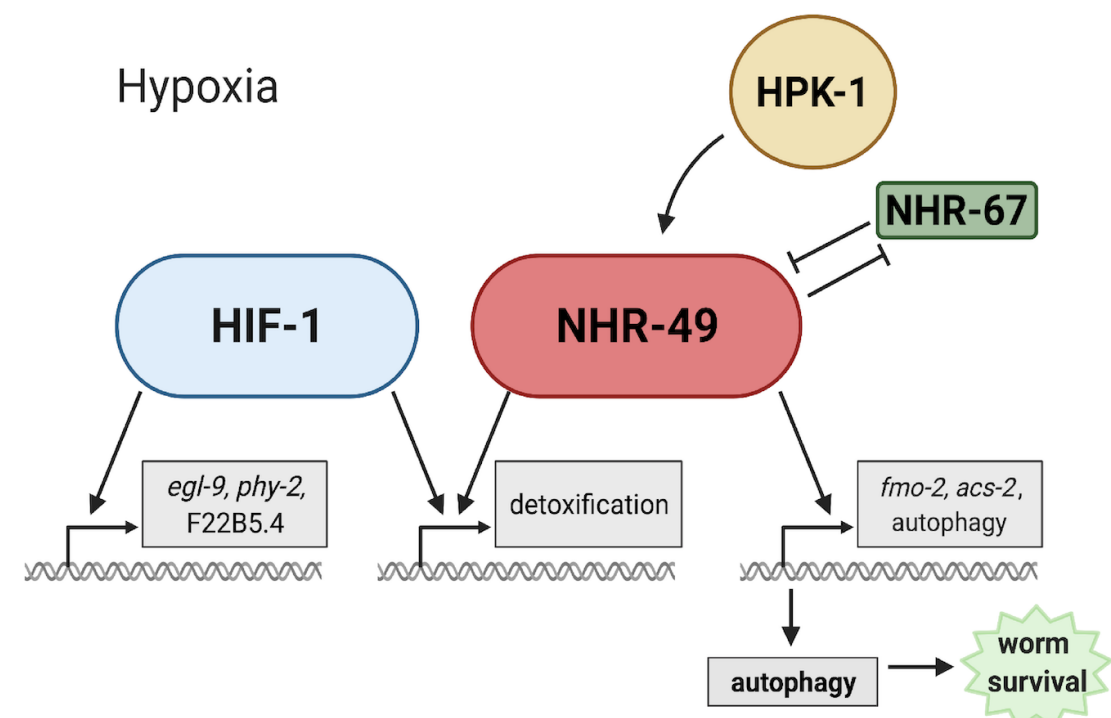


bioRxiv preprint doi: https://doi.org/10.1101/2021.02.24.432575; this version posted February 24, 2021. The copyright holder for this preprint (which was not certified by peer review) is the author/funder. All rights reserved. No reuse allowed without permission.

Doering et al. Hypoxia

1020

$\lfloor 021$

1022

1023

1024

1025

1026

1027

1028

$\lfloor 029$

1030

$\lfloor 031$

1032

1033

1035

$\lfloor 036$

1037

1038

1039

1040

1041

1042

1044

\section{Supplementary Figures}

Supplementary Figure 1. nhr-49 and hif-1 mutants do not display developmental defects

\section{in normoxia.}

(A) The graph shows the average developmental success of wild-type, nhr-49(nr2041), hif1(ia4), and $n h r-49(n r 2041)$; hif-1(ia4) worm embryos kept in $21 \% \mathrm{O}_{2}$ for $65 \mathrm{hr}$, and counted as ability to reach at least L4 stage (three repeats totalling $>100$ individual worms per strain). All comparisons not significant (ordinary one-way ANOVA corrected for multiple comparisons using the Tukey method). (B) The graph shows the average developmental success of wild-type, $n h r-49(n r 2041)$, hif1(ia4), and $n h r-49(n r 2041)$;hif-1(ia4) larval worms kept in $21 \% \mathrm{O}_{2}$ for $48 \mathrm{hr}$ from L1 stage (four repeats totalling $>60$ individual worms per strain). All comparisons not significant (ordinary one-way ANOVA corrected for multiple comparisons using the Tukey method). WT = wild-type.

\section{Supplementary Figure 2. RNA-seq reveals discrete hypoxia responsive transcriptional}

programs.

(A) The figure shows a Multi-Dimensional Scaling (MDS) plot of the distances between gene expression profiles. Distances on the MDS plot correspond to the root-mean-square average of the largest $200 \log 2$-fold-changes between each pair of samples. (B) The graph shows average transcript levels in counts per million (CPM) of fmo-2 mRNA in L4 wild-type, nhr-49(nr2041), and hif-1(ia4) worms exposed to $0.5 \% \mathrm{O}_{2}$ for $3 \mathrm{hr}$ or kept at $21 \% \mathrm{O}_{2}(\mathrm{n}=3)$. ${ }^{* *} \mathrm{p}<0.01$ (ordinary one-way ANOVA corrected for multiple comparisons using the Tukey method). (C, D) Enriched WormCat (Category 2) categories among genes that are significantly up-regulated over two-fold (C) or down-regulated over two-fold (D) in wild-type worms in $21 \% \mathrm{O}_{2}$ vs. $0.5 \% \mathrm{O}_{2}$ are plotted by $-\log 10 \mathrm{p}$-value. (E, G)

Heatmaps of the expression levels of the (E) 139 genes from three repeats which are significantly induced over two-fold in $21 \% \mathrm{O}_{2}$ vs. $0.5 \% \mathrm{O}_{2}$ in wild-type and $n h r-49$ (nr2041) worms, but not in hif1(ia4), and (G) the 264 genes from three repeats which are significantly induced over two-fold in $21 \%$ 
1045

$\mathrm{O}_{2}$ vs. $0.5 \% \mathrm{O}_{2}$ in wild-type, hif-1(ia4), and $n h r-49$ (nr2041) worms. Genes along the y-axis are colored in each repeat based on their z-scores of the log2-transformed Counts Per Million (CPM) plus 1. (F, H) Network views of the enriched functional categories among the 139 genes which are significantly induced over two-fold in $21 \% \mathrm{O}_{2}$ vs. $0.5 \% \mathrm{O}_{2}$ in wild-type and $n h r-49$ (nr2041) worms, but not in hif1(ia4) (F), and the 264 genes which are significantly induced over two-fold in $21 \% \mathrm{O}_{2}$ vs. $0.5 \% \mathrm{O}_{2}$ in wild-type, hif-1(ia4), and $n h r-49$ (nr2041) worms (H). Edge represents significant gene overlap as defined by a Jaccard Coefficient larger than or equal to $25 \%$. Dot size reflects number of genes in each functional category; colour intensity reflects statistical significance $(-\log 10 \mathrm{p}$-value $)$. WT $=$ wild-type.

\section{Supplementary Figure 3. $n h r-49$ regulates acs-2 induction following exposure to hypoxia.}

(A) The graph shows average fold changes of mRNA levels (relative to unexposed wild-type) in L4 wild-type, $n h r-49(n r 2041)$, and hif-1(ia4) worms exposed to $0.5 \% \mathrm{O}_{2}$ for $3 \mathrm{hr}(\mathrm{n}=3)$. *,** $\mathrm{p}<0.05$, 0.01 (ordinary one-way ANOVA corrected for multiple comparisons using the Tukey method). (B) Representative micrographs show Pacs-2::gfp and Pacs-2::gfp;nhr-49(nr2041) adult worms following $4 \mathrm{hr}$ exposure to $0.5 \% \mathrm{O}_{2}$ and $1 \mathrm{hr}$ recovery in $21 \% \mathrm{O}_{2}$. (C) The graph shows the quantification of intestinal GFP levels in Pacs-2::gfp and Pacs-2::gfp;nhr-49(nr2041) worms following $4 \mathrm{hr}$ exposure to $0.5 \% \mathrm{O}_{2}$ and $1 \mathrm{hr}$ recovery in $21 \% \mathrm{O}_{2}$ (three repeats totalling $>30$ individual worms per strain). $* * * * \mathrm{p}$ $<0.0001$ (ordinary one-way ANOVA corrected for multiple comparisons using the Tukey method). n.s. $=$ not significant, $\mathrm{WT}=$ wild-type .

\section{Supplementary Figure 4. Mutants of downstream transcriptional targets of $n h r-49$ in}

\section{hypoxia do not display functional defects in normoxia.}

(A) The graph shows the average population survival of wild-type, nhr-49(nr2041), fmo2(ok2147), acs-2(ok2457), and fmo-2(ok2147); acs-2(ok2457) worm embryos kept in $21 \% \mathrm{O}_{2}$ for $65 \mathrm{hr}$, and counted as ability to reach at least L4 stage (three repeats totalling $>100$ individual worms per 
1070

strain). All comparisons not significant (ordinary one-way ANOVA corrected for multiple comparisons using the Tukey method). (B) The graph shows the average population survival of second generation wild-type and $n h r-49(n r 2041)$ worm embryos fed $\mathrm{EV}, n h r-49$, atg-10, atg-7, bec-1, or epg-3 RNAi kept in $21 \% \mathrm{O}_{2}$ for $65 \mathrm{hr}$, and counted as ability to reach at least L4 stage (three repeats totalling $>100$ individual worms per strain). All comparisons not significant (ordinary one-way ANOVA corrected for multiple comparisons using the Tukey method). WT = wild-type.

\section{Supplementary Figure 5. $n h r-67$ is functionally required for survival in hypoxia.}

(A) The graph shows average fold changes of mRNA levels (relative to wild-type) in L4 wildtype and $n h r-49(e t 13)$ worms $(\mathrm{n}=3$; ordinary one-way ANOVA corrected for multiple comparisons using the Tukey method). (B-C) Representative micrographs (B) and quantification (C) of intestinal GFP levels in Pfmo-2::gfp;nhr-49(et13) adult worms fed EV or $n h r-67$ RNAi kept in $21 \% \mathrm{O}_{2}$ (three repeats totalling $>30$ individual worms per strain). ${ }^{* *} \mathrm{p}<0.01$ (ordinary one-way ANOVA corrected for multiple comparisons using the Tukey method). (D) The graph shows average population survival of second generation wild-type worm embryos fed EV, $n h r-49$, or $n h r-67$ RNAi following $24 \mathrm{hr}$ exposure to $0.5 \% \mathrm{O}_{2}$, then allowed to recover at $21 \% \mathrm{O}_{2}$ for $65 \mathrm{hr}$, and counted as ability to reach at least L4 stage (four repeats totalling $>100$ individual worms per strain). *, $* * \mathrm{p}<0.05,0.01$ vs. EV (RNAi) worms (ordinary one-way ANOVA corrected for multiple comparisons using the Tukey method). (E) The graph shows the average population survival of second generation wild-type worm embryos fed EV, $n h r-49$, or $n h r-67 \mathrm{RNAi}$ kept in $21 \% \mathrm{O}_{2}$ for $65 \mathrm{hr}$, and counted as ability to reach at least L4 stage (four repeats totalling $>100$ individual worms per strain). All comparisons not significant (ordinary one-way ANOVA corrected for multiple comparisons using the Tukey method). n.s. $=$ not significant, $\mathrm{WT}=$ wild-type. 
(A, B) Representative micrographs (A) and quantification (B) of intestinal GFP levels in Pfmo$2:: g f p ; n h r-49$ (et 13) adult worms fed EV, $n h r-49$, hif-1, or $h p k-1$ RNAi kept in $21 \% \mathrm{O}_{2}$ (three or more repeats totalling $>30$ individual worms per strain). $* * * * \mathrm{p}<0.0001$ vs. $E V(R N A i)$ (ordinary one-way ANOVA corrected for multiple comparisons using the Tukey method). (C) The graph shows average population survival of wild-type, $n h r-49(n r 2041), h p k-1(p k 1393)$, and nhr-49(nr2041); hpk-1(pk1393)

totalling $>100$ individual worms per strain). All comparisons not significant (ordinary one-way

ANOVA corrected for multiple comparisons using the Tukey method). (D) The graph shows average

population survival of wild-type, hif-1(ia4), hpk-1(pk1393), and hif-1(ia4);hpk-1(pk1393) worm

embryos kept in $21 \% \mathrm{O}_{2}$ for $65 \mathrm{hr}$, and counted as ability to reach at least L4 stage (four repeats

totalling $>60$ individual worms per strain). All comparisons not significant (ordinary one-way ANOVA

corrected for multiple comparisons using the Tukey method). n.s. = not significant, WT = wild-type.

Supplementary Figure 7. $h p k-1$ is post-transcriptionally regulated in hypoxia.

(A) Representative micrographs show Phpk-1::gfp adult worms in 21\% $\mathrm{O}_{2}$ or following $4 \mathrm{hr}$ exposure to $0.5 \% \mathrm{O}_{2}$ and $1 \mathrm{hr}$ recovery in $21 \% \mathrm{O}_{2}$. (B) Quantification of whole worm GFP levels in Phpk-1::gfp worms following $4 \mathrm{hr}$ exposure to $0.5 \% \mathrm{O}_{2}$ and $1 \mathrm{hr}$ recovery in $21 \% \mathrm{O}_{2}$ or kept at $21 \% \mathrm{O}_{2}$

$\lfloor 112$ (four repeats totalling >30 individual worms per strain; ordinary one-way ANOVA corrected for multiple comparisons using the Tukey method). n.s. = not significant. 
bioRxiv preprint doi: https://doi.org/10.1101/2021.02.24.432575; this version posted February 24, 2021. The copyright holder for this preprint (which was not certified by peer review) is the author/funder. All rights reserved. No reuse allowed without permission. Supplementary Figure 1

A

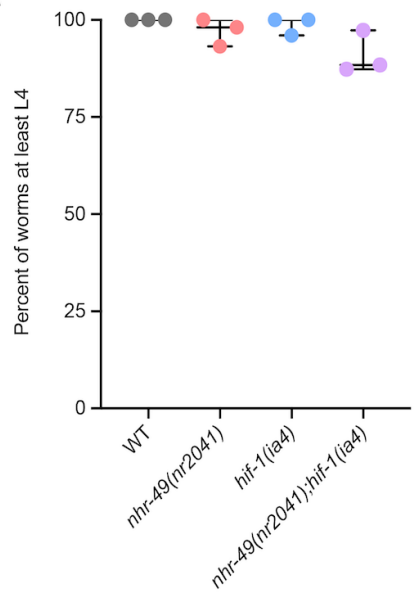

B

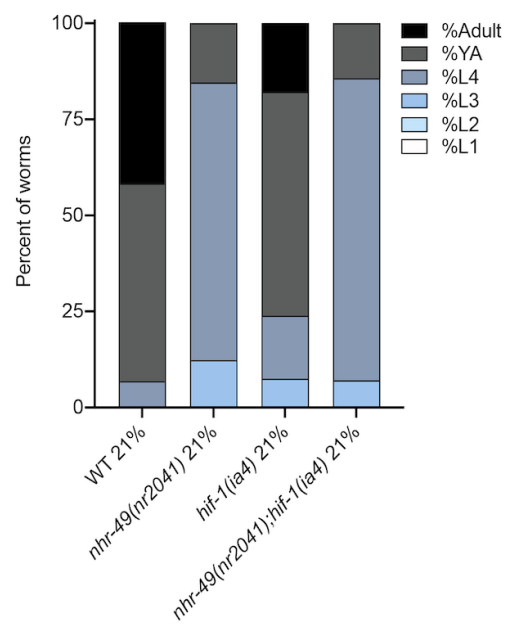


bioRxiv preprint doi: https://doi.org/10.1101/2021.02.24.432575; this version posted February 24, 2021. The copyright holder for this preprint Supplementary Figure 2 was not certified by peer review) is the author/funder. All rights reserved. No reuse allowed without permission.

A

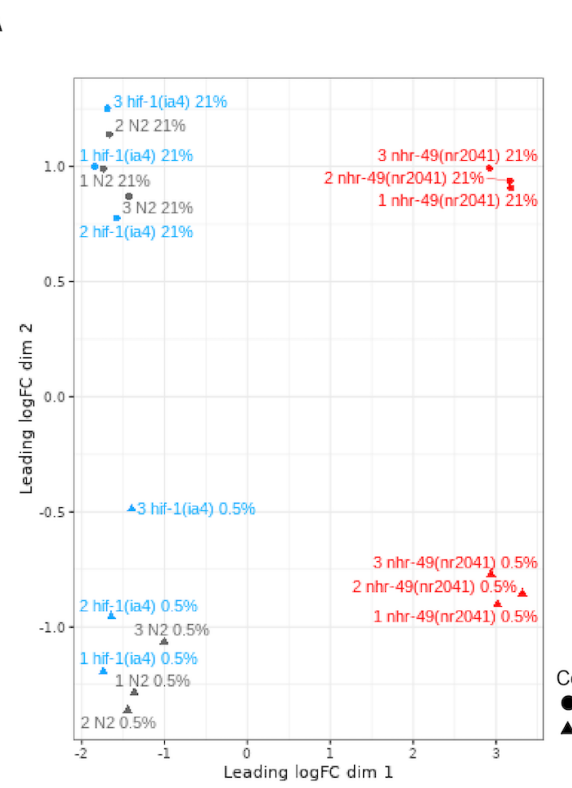

E

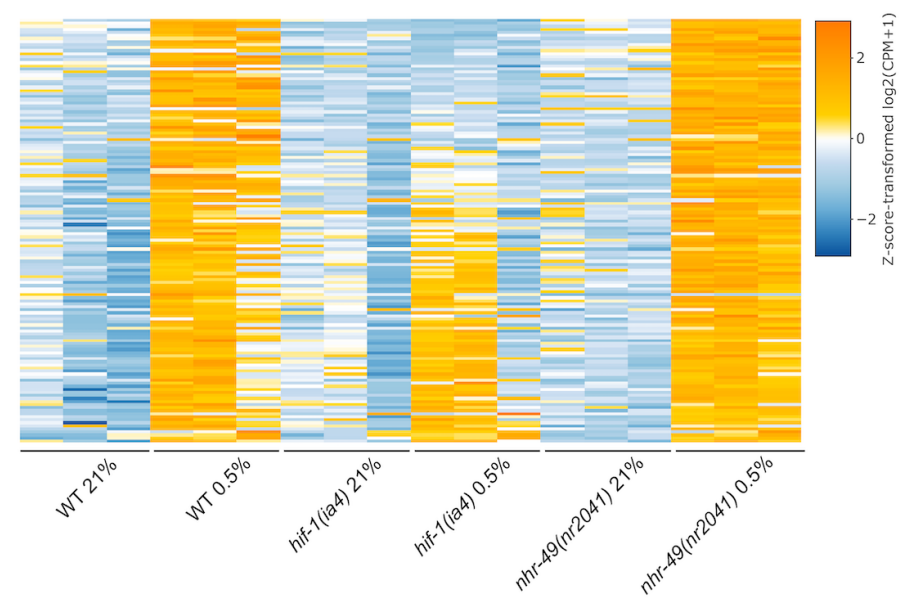

G

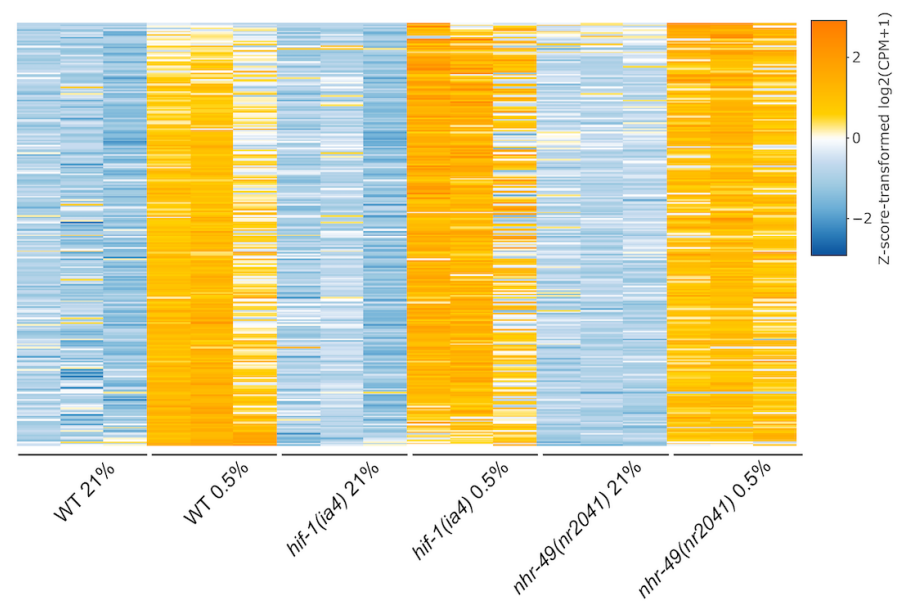

B

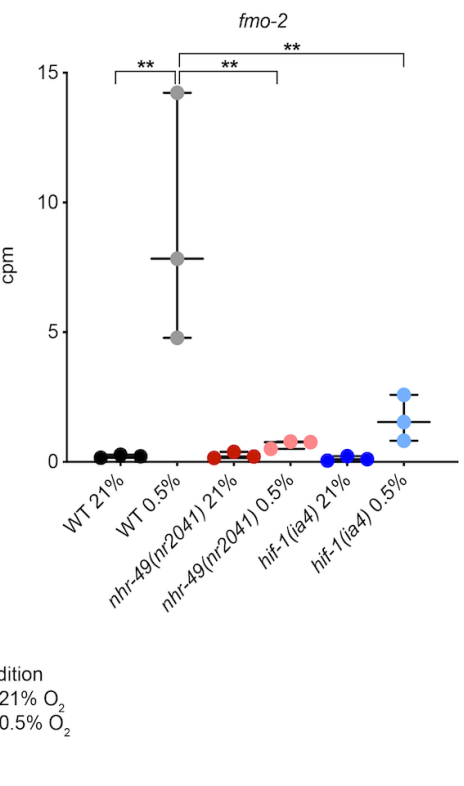

C

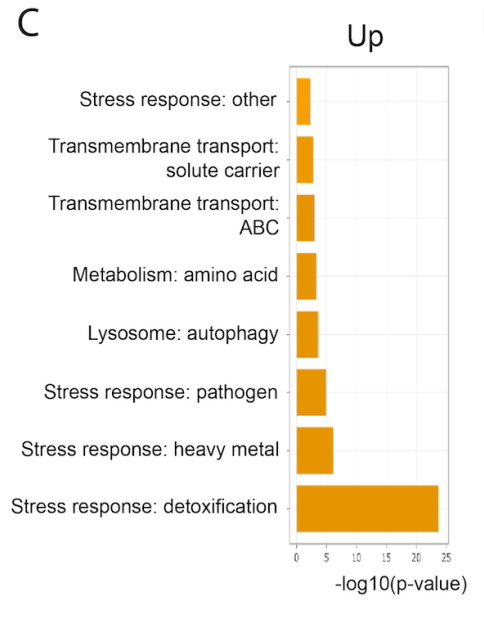

D

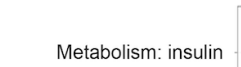

Metabolism: amino acid Transmembrane transport: major facilitator

Transmembrane transport: solute carrier

Transmembrane transport: amino acid

Stress response: GST Down

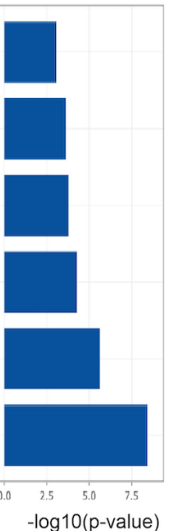

F

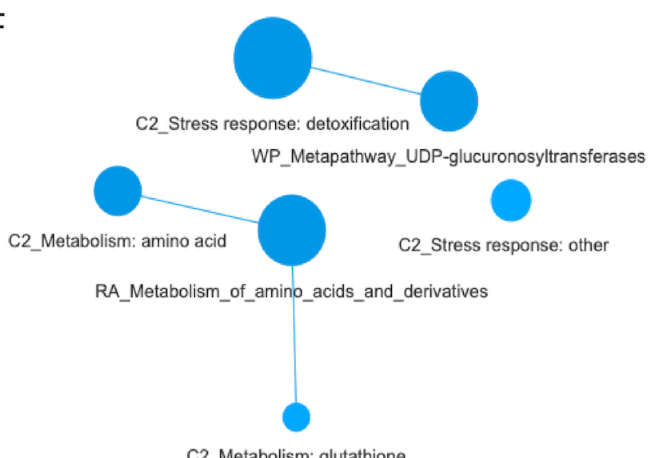

C2 Metabolism: glutathione

\section{$\mathrm{H}$}

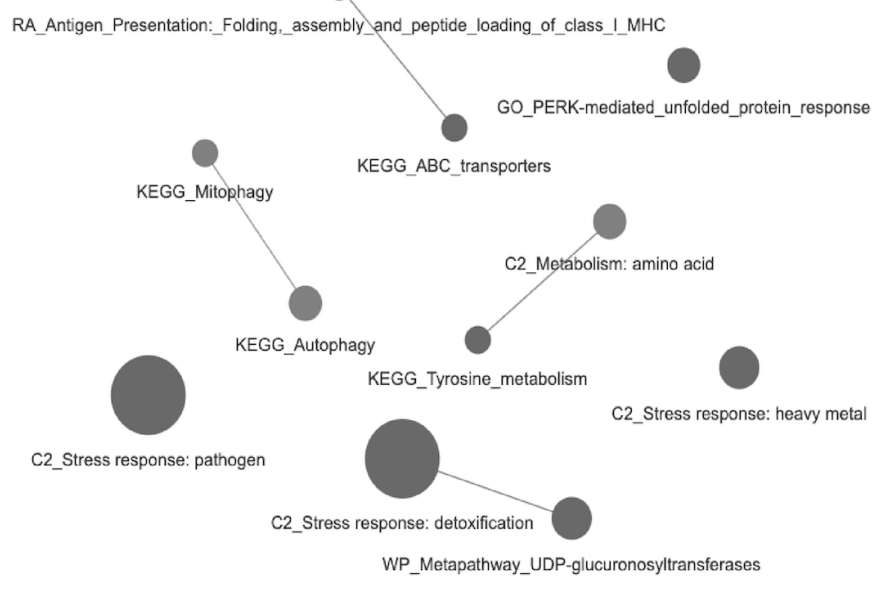


bioRxiv preprint doi: https://doi.org/10.1101/2021.02.24.432575; this version posted February 24, 2021. The copyright holder for this preprint (which was not certified by peer review) is the author/funder. All rights reserved. No reuse allowed without permission.

Supplementary Figure 3

A

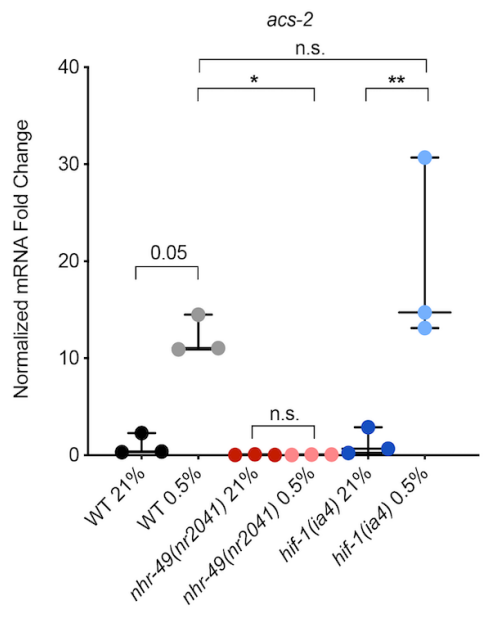

B

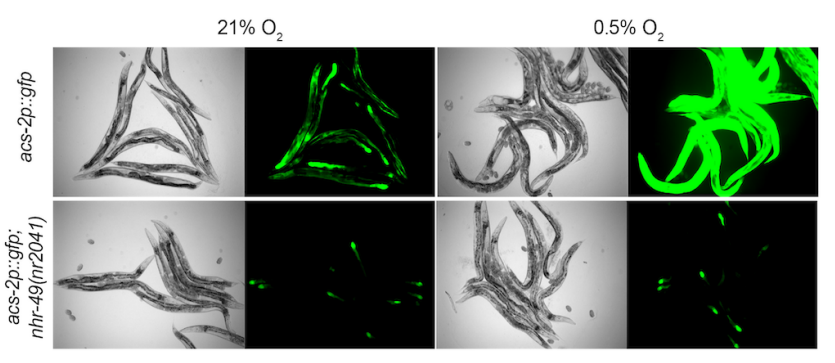

C

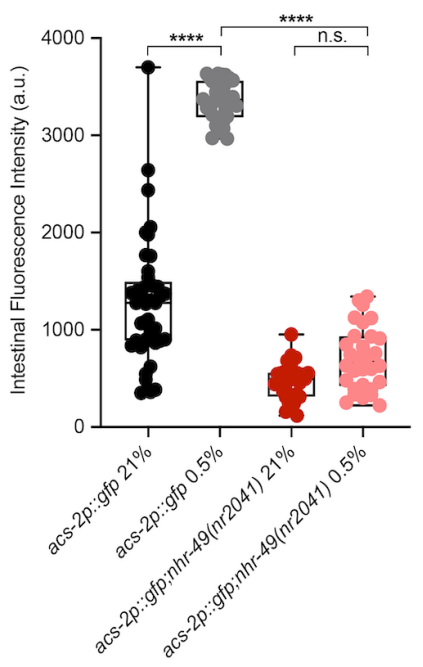


bioRxiv preprint doi: https://doi.org/10.1101/2021.02.24.432575; this version posted February 24, 2021. The copyright holder for this preprint (which was not certified by peer review) is the author/funder. All rights reserved. No reuse allowed without permission. Supplementary Figure 4

A

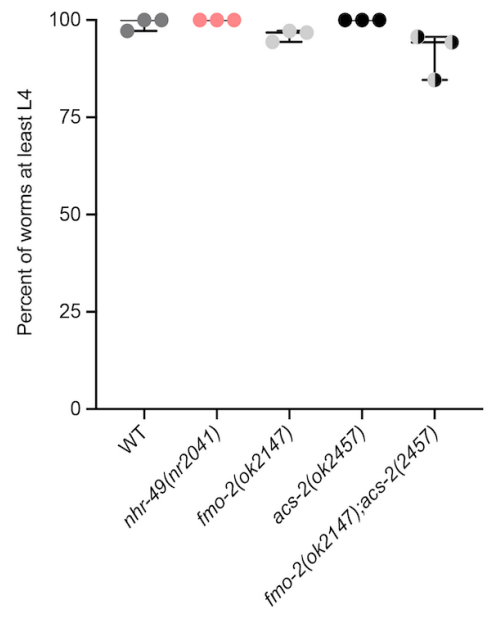

B

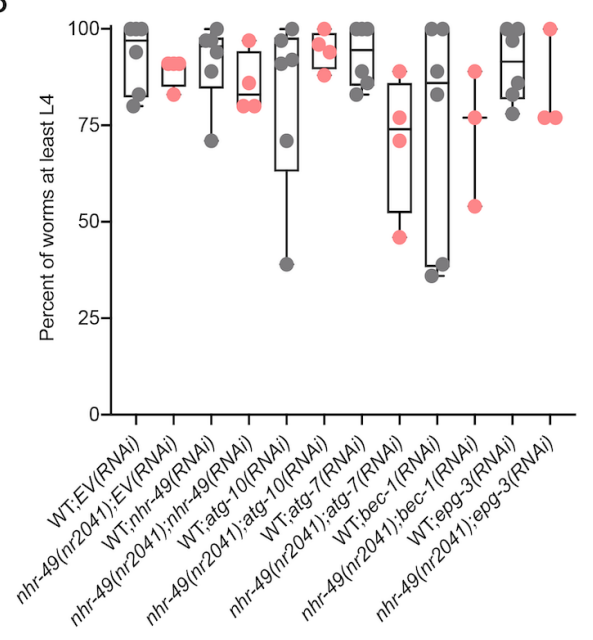


bioRxiv preprint doi: https://doi.org/10.1101/2021.02.24.432575; this version posted February 24, 2021. The copyright holder for this preprint (which was not certified by peer review) is the author/funder. All rights reserved. No reuse allowed without permission.

Supplementary Figure 5

A

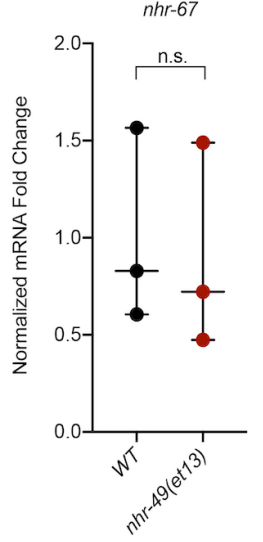

D

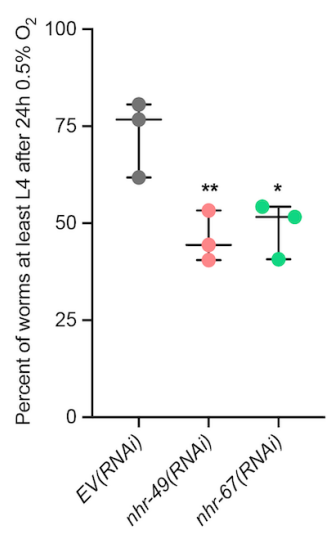

B

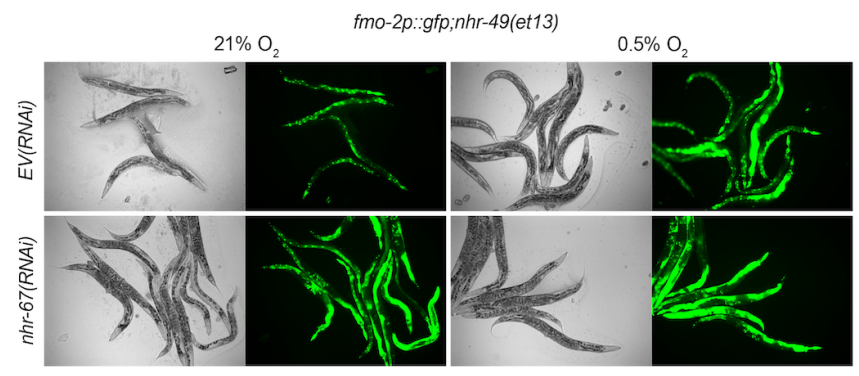

E

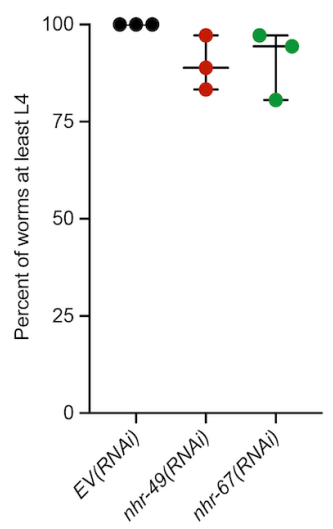

C

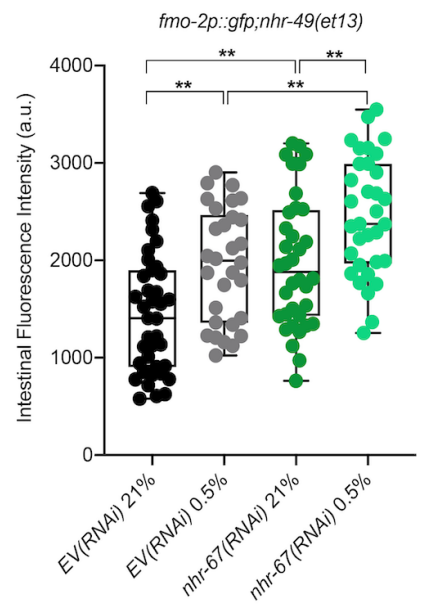


bioRxiv preprint doi: https://doi.org/10.1101/2021.02.24.432575; this version posted February 24, 2021. The copyright holder for this preprint Supplementary Figure 6 was not certified by peer review) is the author/funder. All rights reserved. No reuse allowed without permission.

A

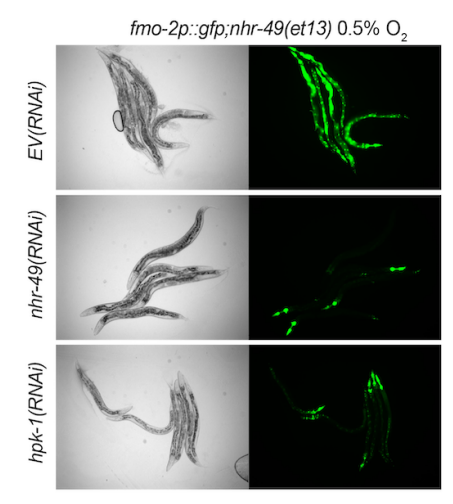

C

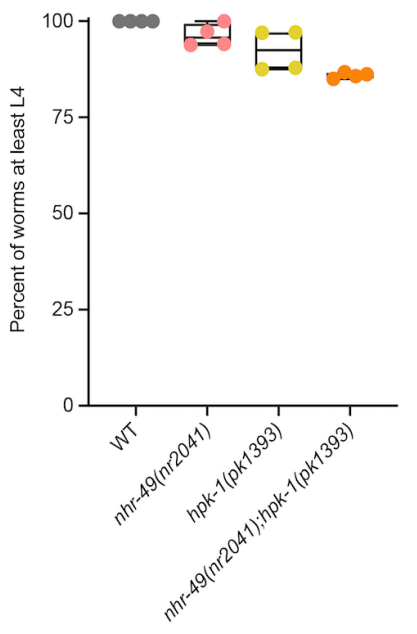

B

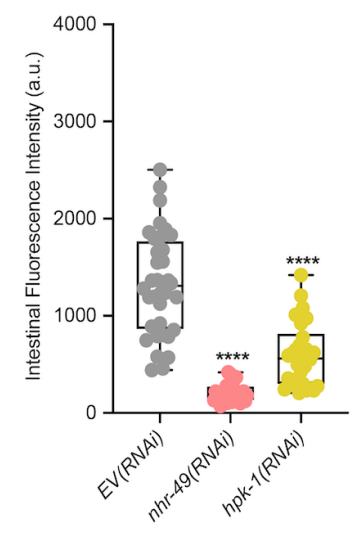

D

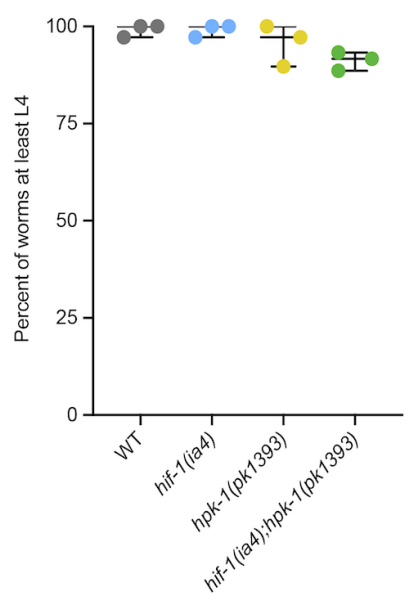


bioRxiv preprint doi: https://doi.org/10.1101/2021.02.24.432575; this version posted February 24, 2021. The copyright holder for this preprint (which was not certified by peer review) is the author/funder. All rights reserved. No reuse allowed without permission. Supplementary Figure 7

A

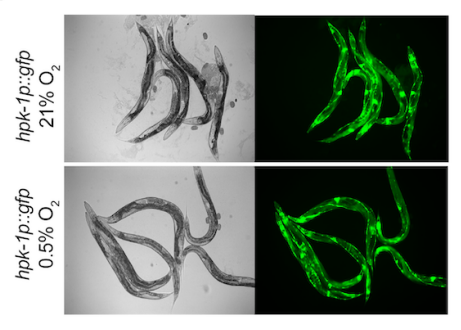

B

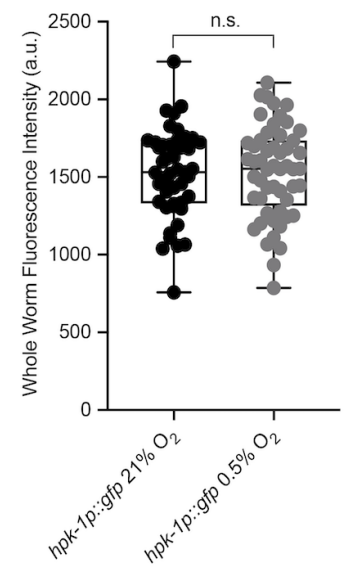




\section{$\lfloor 115$ Supplementary Tables}

\section{\116 Supplementary Table 1. Statistical comparison of each genotype's ability to reach at least L4}

$\left\lfloor 117\right.$ following $24 \mathrm{hr}$ exposure to $0.5 \% \mathrm{O}_{2}$ as embryo and then allowed to recover at $21 \% \mathrm{O}_{2}$ for $65 \mathrm{hr}$,

$\left\lfloor 118\right.$ compared to worm embryos kept in $21 \% \mathrm{O}_{2}$ for $65 \mathrm{hr}$.

\begin{tabular}{|c|c|c|c|}
\hline $0.5 \% \mathrm{O}_{2}$ Figure & $21 \% \mathrm{O}_{2}$ Figure & Genotype & p-value \\
\hline Figure $2 \mathrm{~A}$ & Supplementary Figure 1A & WT & 0.4943 \\
\hline Figure $2 \mathrm{~A}$ & Supplementary Figure 1A & $n h r-49(n r 2041)$ & $<0.0001 * * * *$ \\
\hline Figure $2 \mathrm{~A}$ & Supplementary Figure 1A & hif-1(ia4) & $<0.0001 * * * *$ \\
\hline Figure $2 \mathrm{~A}$ & Supplementary Figure 1A & $n h r-49(n r 2041) ; h i f-1($ ia4 $)$ & $<0.0001 * * * *$ \\
\hline Figure 3D & Supplementary Figure 4A & WT & 0.1403 \\
\hline Figure 3D & Supplementary Figure 4A & $n h r-49(n r 2041)$ & $<0.0001 * * * *$ \\
\hline Figure 3D & Supplementary Figure 4A & fmo-2(ok2147) & $0.0005 * * *$ \\
\hline Figure 3D & Supplementary Figure 4A & acs-2(ok2457) & $0.0008 * * *$ \\
\hline Figure 3D & Supplementary Figure 4A & fmo-2(ok2147);acs-2(ok2157) & $<0.0001 * * * *$ \\
\hline Figure $3 \mathrm{E}$ & Supplementary Figure 4B & $\mathrm{WT} ; E V(R N A i)$ & 0.9995 \\
\hline Figure $3 \mathrm{E}$ & Supplementary Figure 4B & $n h r-49(n r 2041) ; E V(R N A i)$ & $0.0003 * * *$ \\
\hline Figure $3 \mathrm{E}$ & Supplementary Figure 4B & $\mathrm{WT} ; n h r-49(R N A i)$ & $0.0001 * * *$ \\
\hline Figure $3 \mathrm{E}$ & Supplementary Figure 4B & $n h r-49(n r 2041) ; n h r-49(R N A i)$ & $0.0002 * * *$ \\
\hline Figure $3 \mathrm{E}$ & Supplementary Figure 4B & WT;atg-10(RNAi) & $0.0001 * * *$ \\
\hline Figure $3 \mathrm{E}$ & Supplementary Figure 4B & nhr-49(nr2041);atg-10(RNAi) & $0.0021 * *$ \\
\hline Figure $3 \mathrm{E}$ & Supplementary Figure 4B & WT; atg-7(RNAi) & $0.0003 * * *$ \\
\hline Figure $3 \mathrm{E}$ & Supplementary Figure 4B & nhr-49(nr2041);atg-7(RNAi) & 0.0534 \\
\hline Figure $3 \mathrm{E}$ & Supplementary Figure 4B & WT;bec-1(RNAi) & $0.0015 * *$ \\
\hline Figure 3E & Supplementary Figure 4B & $n h r-49(n r 2041) ; b e c-1(R N A i)$ & $0.0033 * *$ \\
\hline
\end{tabular}


Doering et al. Hypoxia

\begin{tabular}{|l|l|l|l|}
\hline Figure 3E & Supplementary Figure 4B & WT;epg-3(RNAi) & $0.0006^{* * *}$ \\
\hline Figure 3E & Supplementary Figure 4B & $n h r-49(n r 2041) ; e p g-3(R N A i)$ & $0.0001^{* * *}$ \\
\hline Supplementary Figure 5D & Supplementary Figure 5E & EV(RNAi) & $0.0072^{* *}$ \\
\hline Supplementary Figure 5D & Supplementary Figure 5E & $n h r-49(R N A i)$ & $0.0001^{* * *}$ \\
\hline Supplementary Figure 5D & Supplementary Figure 5E & $n h r-67(R N A i)$ & $0.0002^{* * *}$ \\
\hline Figure 6F & Supplementary Figure 6C & WT & 0.9119 \\
\hline Figure 6F & Supplementary Figure 6C & $n h r-49(n r 2041)$ & $<0.0001^{* * * *}$ \\
\hline Figure 6F & Supplementary Figure 6C & $h p k-1(p k 1393)$ & $<0.0001^{* * * *}$ \\
\hline Figure 6F & Supplementary Figure 6C & $n h r-49(n r 2041) ; h p k-1(p k 1393)$ & $<0.0001^{* * * *}$ \\
\hline Figure 6G & Supplementary Figure 6D & WT & $0.0223^{*}$ \\
\hline Figure 6G & Supplementary Figure 6D & hif-1(ia4) & $<0.0001^{* * * *}$ \\
\hline Figure 6G & Supplementary Figure 6D & hpk-1(pk1393) & $<0.0001^{* * * *}$ \\
\hline Figure 6G & Supplementary Figure 6D & hif-1(ia4);hpk-1(pk1393) & $<0.0001^{* * * *}$ \\
\hline
\end{tabular}

$\lfloor 119$ All p-values are derived using ordinary one-way ANOVA corrected for multiple comparisons using the

120 Tukey method. $* \mathrm{p}<0.05, * * \mathrm{p}<0.01, * * * \mathrm{p}<0.001$, and $* * * * \mathrm{p}<0.0001$. WT $=$ wild-type.

Supplementary Table 2. Statistical comparison of each genotype's ability to reach at least L4

$21 \% \mathrm{O}_{2}$ for $48 \mathrm{hr}$.

\begin{tabular}{|l|l|l|l|}
\hline \multicolumn{1}{|c|}{$\mathbf{0 . 5 \%} \mathrm{O}_{2}$ Figure } & \multicolumn{1}{|c|}{$\mathbf{2 1 \%} \mathrm{O}_{2}$ Figure } & \multicolumn{1}{c|}{ Genotype } & p-value \\
\hline Figure 2B & Supplementary Figure 1B & WT & $>0.9999$ \\
\hline Figure 2B & Supplementary Figure 1B & $n h r-49(n r 2041)$ & $0.0028^{* *}$ \\
\hline Figure 2B & Supplementary Figure 1B & hif-1(ia4) & $0.0021^{* *}$ \\
\hline Figure 2B & Supplementary Figure 1B & nhr-49(nr2041);hif-1(ia4) & $<0.0001 * * * *$ \\
\hline
\end{tabular}


$\lfloor 125$ All p-values are derived using ordinary one-way ANOVA corrected for multiple comparisons using the

$\lfloor 126$ Tukey method. $* * \mathrm{p}<0.01$ and $* * * * \mathrm{p}<0.0001 . \mathrm{WT}=$ wild-type.

$\lfloor 127$

$\left\lfloor 128\right.$ Supplementary Table 3. List of the 83 genes upregulated more than two-fold in $21 \% \mathbf{O}_{2}$ vs. $0.5 \%$

$\left\lfloor 129 \mathbf{O}_{2}\right.$ in wild-type and hif-1(ia4) worms, but not in $n h r-49(n r 2041)$ worms, i.e. $n h r-49$-dependent,

$\lfloor 130 \quad$ hif-1-independent genes.

\begin{tabular}{|l|l|l|l|l|l|l|}
\hline ABHD-5.1 & C42D4.1 & CYP-37B1 & FAAH-2 & MNK-1 & R10D12.6 & TBC-14 \\
\hline ACS-2 & C49G7.12 & CYP-43A1* & FBXA-98 & NHL-3 & SIAH-1 & UGT-2* \\
\hline AKT-2 & C49G7.7 & EEED8.2 & FBXA-99 & NHR-131 & SRH-2 & UGT-20* \\
\hline ATG-2 & C50F7.5 & EPG-9 & FMO-2 & NHR-238 & SRR-6 & UGT-51* \\
\hline B0228.6 & CBP-3 & F13E9.15 & GBA-2 & NHR-65 & SRT-39 & VEM-1 \\
\hline B0403.3 & CUP-16 & F16B12.4 & ICL-1 & NHR-88 & SRW-86 & W09G12.7 \\
\hline C01B4.7 & CYP-13A11 & F16C3.2 & K09D9.1 & NUMR-2 & SYX-2 & Y19D10A.4 \\
\hline C06E4.6 & CYP-13A5* & F20B6.7 & K09E9.1 & OAC-14 & T04H1.2 & Y38C1AA.6 \\
\hline C18B12.4 & CYP-13A6* & F22F7.4 & LGC-1 & OAC-6 & T16G1.4 & Y43F8C.3 \\
\hline C25F9.11 & CYP-25A3* & F35E8.2 & LGG-2 & PALS-14 & T21B4.21 & Y77E11A.2 \\
\hline C33A11.2 & CYP-34A9* & F43G6.8 & M01A8.1 & R03H10.6 & T22C8.6 & ZIP-5 \\
\hline C33A12.3 & CYP-35A1 & F59C6.16 & MFB-1 & R09D1.12 & T24E12.5 & \\
\hline
\end{tabular}

* genes involved in detoxification response

Supplementary Table 4. List of 139 genes upregulated more than two-fold in $21 \% \mathrm{O}_{2}$ vs. $0.5 \% \mathrm{O}_{2}$

in wild-type and $n h r-49(n r 2041)$ worms, but not in hif-1(ia4) worms, i.e. hif-1-dependent, nhr-49-

independent genes.

\begin{tabular}{|l|l|l|l|l|l|l|}
\hline ACS-12 & C52E2.5 & F07C3.9 & FBXA-50 & MMAA-1 & SQRD-1 & UGT-5* \\
\hline B0507.6 & C56E6.2 & F13H8.11 & FMO-4 & NAS-28 & SRD-35 & UGT-50* \\
\hline BATH-36 & CBP-2 & F16H6.10 & FRM-10 & NHR-161 & SRH-283 & W07A12.4 \\
\hline C06G3.6 & CEEH-1 & F17C11.11 & GBH-2 & NHR-173 & SRX-12 & Y102A11A.9 \\
\hline C08B6.2 & CHIL-13 & F22B3.7 & GCL-1 & NHR-195 & SRX-125 & Y105C5B.25 \\
\hline C10C5.5 & CLEC-144 & F22B5.4 & GLB-1 & NHR-210 & SRX-21 & Y116A8C.25 \\
\hline C14B9.3 & CLEC-222 & F25E5.4 & GLB-15 & NHR-42 & T04A11.1 & Y17G7B.8 \\
\hline C15B12.8 & CLEC-223 & F29C6.1 & HGO-1 & NHR-59 & T07G12.5 & Y32B12C.1 \\
\hline C18H9.5 & COMT-4 & F35E12.9 & K04C1.3 & NLG-1 & T20D4.3 & Y40H7A.11 \\
\hline C25F9.5 & CYP-13A3* & F37H8.2 & K05C4.9 & OAC-31 & T24A6.7 & Y43F8B.13 \\
\hline
\end{tabular}


Doering et al. Hypoxia

\begin{tabular}{|l|l|l|l|l|l|l|}
\hline C31H5.5 & CYP-14A2* & F42C5.4 & K08B4.7 & OAC-54 & T28F3.5 & Y43F8B.15 \\
\hline C32D5.12 & D1054.18 & F42G2.2 & K11D12.13 & OAC-7 & T28H10.1 & Y43F8B.23 \\
\hline C32E8.9 & DDO-1 & F45D11.14 & K11G9.1 & PCK-1 & T28H10.3 & Y47H10A.5 \\
\hline C33D9.6 & DEL-5 & F47H4.2 & KMO-1 & PCP-2 & TBC-6 & Y4C6B.4 \\
\hline C34D1.4 & DH11.2 & F53C3.4 & LINC-72 & PGP-7 & TPRA-1 & Y53G8B.2 \\
\hline C34D10.2 & E02C12.10 & F56D2.5 & M01H9.2 & PHY-2 & TPS-2 & Y57A10A.14 \\
\hline C37C3.10 & ECH-9 & F57B9.1 & M03A1.3 & R05G6.10 & TWK-31 & Y5H2B.1 \\
\hline C44C1.6 & EFK-1 & FBXA-188 & MADF-10 & R07E4.1 & UGT-17* & ZK228.4 \\
\hline C44E12.1 & EGL-9 & FBXA-25 & MATH-27 & R08D7.7 & UGT-24* & ZK550.6 \\
\hline C49C3.15 & ETHE-1 & FBXA-26 & MCE-1 & SKR-5 & UGT-4* & \\
\hline
\end{tabular}

* genes involved in detoxification response

$\left\lfloor 138\right.$ Supplementary Table 5. List of 264 genes upregulated more than two-fold in $21 \% \mathbf{O}_{2}$ vs. $0.5 \% \mathbf{O}_{2}$

via RNA-seq in wild-type, $n h r-49(n r 2041)$, and hif-1(ia4).

\begin{tabular}{|c|c|c|c|c|c|c|}
\hline AAKG-4 & CATP-3 & F21D12.3 & FBXA-82 & M01H9.3 & SLC-17.4 & UGT-19* \\
\hline ARRD-11 & CDR-2 & F22H10.2 & FBXA-91 & M163.1 & SLC-36.5 & UGT-33* \\
\hline ARRD-24 & CHIL-18 & F25B3.5 & FBXA-92 & M60.7 & SODH-1 & UGT-54* \\
\hline ARRD-8 & CKR-2 & F26F12.3 & FBXL-1 & MAI-1 & SQST-1 & W04C9.8 \\
\hline B0205.13 & CNC-2 & F27D9.2 & FIPR-22 & MTL-1 & SRD-27 & W05H9.1 \\
\hline B0205.14 & CNC-4 & F28H1.1 & FIPR-24 & NEP-26 & SRH-48 & Y15E3A.5 \\
\hline B0310.3 & CNG-1 & F28H6.8 & FIPR-26 & NHR-103 & SRI-36 & Y34F4.4 \\
\hline B0462.5 & COEL-1 & F33H12.7 & FKH-7 & NHR-107 & SRI-39 & Y34F4.7 \\
\hline BEST-5 & COMT-5 & F34H10.3 & FTN-1 & NHR-115 & SRM-3 & Y37A1B.5 \\
\hline BIGR-1 & CYP-13A8* & F37A8.5 & GEM-4 & NHR-126 & SRP-8 & Y38H6C.9 \\
\hline C02F5.12 & CYP-14A1* & F40F12.9 & GLO-3 & NHR-132 & STO-1 & Y39A3A.4 \\
\hline C04A11.5 & CYP-14A4* & F41E6.5 & GPA-1 & NHR-18 & STR-31 & Y42G9A.1 \\
\hline C04C11.25 & CYP-14A5 & $\mathrm{F} 43 \mathrm{C} 1.7$ & H28G03.1 & NHR-211 & SWT-1 & Y43F8B.14 \\
\hline C06B3.6 & CYP-32B1* & F43C11.7 & HAF-7 & NHR-212 & T05H4.15 & Y43F8B.9 \\
\hline C06B3.7 & CYP-33C7 & F43H9.4 & HIL-1 & NHR-226 & T08A9.13 & Y44A6C.1 \\
\hline C06E1.11 & CYP-33C8* & F45D3.4 & HPD-1 & NHR-228 & T09F5.12 & Y45F10D.6 \\
\hline C08E8.4 & D1086.5 & F45E1.5 & HRG-1 & NHR-230 & T10C6.15 & Y46G5A.36 \\
\hline C08F11.13 & DAAO-1 & F46A8.13 & HRG-2 & NHR-57 & T10G3.1 & Y47G6A.5 \\
\hline C10C5.2 & DC2.5 & F47B10.9 & HSP-12.3 & NHR-79 & T10H9.8 & Y47H10A.3 \\
\hline C11G10.1 & DCT-1 & F47B8.3 & HSP-70 & NHR-90 & T12A7.6 & Y54G11A.7 \\
\hline C18A11.1 & DCT-7 & F47B8.4 & IRG-2 & NHR-99 & T12D8.5 & Y54G2A.11 \\
\hline $\mathrm{C} 23 \mathrm{H} 4.2$ & DCT-8 & F53A9.7 & IST-1 & NIPI-3 & T16G1.5 & Y54G2A.36 \\
\hline $\mathrm{C} 23 \mathrm{H} 4.6$ & DOD-3 & F53B2.8 & K01C8.1 & NNT-1 & T19C4.5 & Y54G2A.52 \\
\hline C24B5.4 & E03H4.8 & F53C3.6 & K01F9.2 & PALS-34 & T20D4.7 & Y56A3A.33 \\
\hline
\end{tabular}


Doering et al. Hypoxia

\begin{tabular}{|l|l|l|l|l|l|l|}
\hline C25F9.12 & E04F6.6 & F54B8.4 & K02D7.1 & PALS-6 & T24C4.4 & Y58A7A.3 \\
\hline C28G1.6 & EGAP1.1 & F55C12.19 & K05B2.4 & PARG-2 & T27F6.8 & Y58A7A.4 \\
\hline C29F7.2 & F08G12.5 & F56C4.4 & K06A9.2 & PCS-1 & T28B8.1 & Y58A7A.5 \\
\hline C31H2.4 & F09F7.6 & F56D6.8 & K06G5.3 & PEK-1 & T28F4.4 & Y6E2A.4 \\
\hline C33D9.13 & F10E9.12 & F57B9.3 & K08D8.12 & PGP-3 & T28F4.5 & Y6G8.2 \\
\hline C35A5.6 & F13C5.1 & F58G6.9 & K08D9.4 & PGP-9 & TLI-1 & Y71G12B.2 \\
\hline C36B1.6 & F13D11.3 & F59B10.4 & K09C8.7 & PITR-5 & TOS-1 & ZC239.14 \\
\hline C37A5.3 & F14F9.2 & F59E11.7 & K10G4.3 & PTR-22 & TSP-1 & ZC395.5 \\
\hline C44H9.5 & F14F9.3 & FBXA-105 & K10G6.9 & R06B9.5 & TTR-23 & ZC443.3 \\
\hline C46C2.2 & F14F9.4 & FBXA-163 & K12H6.6 & R06C1.6 & TTR-37 & ZC443.4 \\
\hline C49G7.10 & F15A8.6 & FBXA-189 & KGB-2 & R08F11.4 & TTS-1 & ZIG-7 \\
\hline C54F6.18 & F15E6.3 & FBXA-24 & KREG-1 & R102.1 & UBC-8 & ZK836.3 \\
\hline C54G10.1 & F17C11.13 & FBXA-66 & LINC-37 & R186.1 & UGT-13* & \\
\hline CAH-4 & F18G5.6 & FBXA-80 & M01B2.13 & SCL-2 & UGT-18* & \\
\hline
\end{tabular}

* genes involved in detoxification response

Supplementary Table 6. Worm strains used in this study.

\begin{tabular}{|l|l|l|}
\hline Strain & Genotype & Reference \\
\hline N2 & Wild-type & (Brenner, 1974) \\
\hline STE68 & $n h r-49(n r 2041) I$ & $\begin{array}{l}\text { (Marc R. Van Gilst et al., } \\
2005)\end{array}$ \\
\hline VE40 & eavEx20[Pfmo-2::gfp + rol-6(su1006)] & (Goh et al., 2018) \\
\hline STE129 & $n h r-49(n r 2041)$ I; eavEx20[Pfmo-2::gfp + rol-6(su1006)] & This study \\
\hline ZG31 & hif-1(ia4) V & (Jiang et al., 2001) \\
\hline STE130 & $n h r-49(n r 2041) I ;$ hif-1(ia4) $V$ & This study \\
\hline VC1668 & fmo-2(ok2147) IV & (Leiser et al., 2015) \\
\hline RB1899 & acs-2(ok2457) $V$ & (J. Zhang et al., 2011) \\
\hline STE131 & fmo-2(ok2147) IV; acs-2(ok2457) $V$ & This study \\
\hline STE110 & nhr-49Iet13) I & (K. Lee et al., 2016) \\
\hline
\end{tabular}




\begin{tabular}{|c|c|c|}
\hline AGP33a & $\begin{array}{l}n h r-49(n r 2041) I ; g l m E x 5[P n h r-49:: n h r-49:: g f p+\text { Pmyo- } \\
2:: m \text { Cherry] }\end{array}$ & (Naim et al., 2020) \\
\hline AGP65 & $\begin{array}{l}\text { nhr-49(nr2041)I; glmEx9 [Pgly-19::nhr-49::gfp + Pmyo- } \\
2:: m \text { Cherry] }\end{array}$ & (Naim et al., 2020) \\
\hline AGP53 & $\begin{array}{l}\text { nhr-49(nr2041)I; glmEx11 [Pcol-12::nhr-49::gfp + Pmyo- } \\
2:: m \text { Cherry] }\end{array}$ & (Naim et al., 2020) \\
\hline AGP51 & $\begin{array}{l}\text { nhr-49(nr2041)I; glmEx13 [Prgef-1::nhr-49::gfp + Pmyo- } \\
2:: m \text { Cherry] }\end{array}$ & (Naim et al., 2020) \\
\hline WBM170 & wbmEx57 [Pacs-2::gfp + rol-6(su1006)] & (Burkewitz et al., 2015) \\
\hline WBM169 & $n h r-49(n r 2041) I ;$ wbmEx57 [Pacs-2::gfp + rol-6(su1006)] & (Burkewitz et al., 2015) \\
\hline AGP25f & glmEx5 (Pnhr-49::nhr-49::gfp + Pmyo-2::mCherry) & (Ratnappan et al., 2014) \\
\hline EK273 & $h p k-1(p k 1393) X$ & (Raich et al., 2003) \\
\hline STE132 & $n h r-49(n r 2041)$ I; hpk-1(pk1393) X & This study \\
\hline STE133 & hif-1(ia4) V; hpk-1(pk1393) X & This study \\
\hline STE117 & nhr-49(et13) I; eavEx20[Pfmo-2::gfp + rol-6(su1006)] & (Goh et al., 2018) \\
\hline AVS394 & $\operatorname{artEx12}[$ Phpk-1::gfp + rol-6(su1006)] & (Das et al., 2017) \\
\hline
\end{tabular}

$\lfloor 144$ Supplementary Table 7. List of qRT-PCR primer sequences used in this study.

\begin{tabular}{|l|l|l|}
\hline Gene & Forward primer (5'-3') & Reverse Primer (5'-3') \\
\hline$f m o-2$ & GGAACAAGCGTGTTGCTGT & GCCATAGAGAAGACCATGTCG \\
\hline$a c s-2$ & AGTGAGACTTGACAGTTCCG & CTTGTAAGAGAGGAATGGCTC \\
\hline$n h r-49$ & TCCGAGTTCATTCTCGACG & GGATGAATTGCCAATGGAGC \\
\hline$h p k-1$ & TGTCAAAGTGAAGCCGCTGG & CGGCGCCAGTTCGTGTAGTA \\
\hline$n h r-67$ & GAGGATGATGCGACGAGTAG & TGGTCTTGAAGAGGAAGGGGA \\
\hline
\end{tabular}


bioRxiv preprint doi: https://doi.org/10.1101/2021.02.24.432575; this version posted February 24, 2021. The copyright holder for this preprint (which was not certified by peer review) is the author/funder. All rights reserved. No reuse allowed without permission.

Doering et al. Hypoxia

\begin{tabular}{|l|l|l|}
\hline$a c t-1$ & GCTGGACGTGATCTTACTGATTACC & GTAGCAGAGCTTCTCCTTGATGTC \\
\hline$t b a-1$ & GTACACTCCACTGATCTCTGCTGACAAG & CTCTGTACAAGAGGCAAACAGCCATG \\
\hline$u b c-2$ & AGGGAGGTGTCTTCTTCCTCAC & CGGA TTTGGA TCACAGAGCAGC \\
\hline
\end{tabular}

